\title{
The Presynaptic Active Zone Protein RIM1 $\alpha$ Controls Epileptogenesis following Status Epilepticus
}

\author{
Julika Pitsch, ${ }^{1}$ Thoralf Opitz, ${ }^{2}$ Verena Borm, ${ }^{1}$ Anne Woitecki, ${ }^{1}$ Matthäus Staniek,,${ }^{2,3}$ Heinz Beck, ${ }^{2}$ Albert J. Becker, ${ }^{1}$ \\ and Susanne Schoch ${ }^{1}$ \\ ${ }^{1}$ Department of Neuropathology and ${ }^{2}$ Department of Epileptology, Laboratory for Experimental Epileptology and Cognition Research, and ${ }^{3} \mathrm{Helmholtz}-$ \\ Institute for Radiation and Nuclear Physics, University of Bonn, 53105 Bonn, Germany
}

To ensure operation of synaptic transmission within an appropriate dynamic range, neurons have evolved mechanisms of activitydependent plasticity, including changes in presynaptic efficacy. The multidomain protein RIM1 $\alpha$ is an integral component of the cytomatrix at the presynaptic active zone and has emerged as key mediator of presynaptically expressed forms of synaptic plasticity. We have therefore addressed the role of RIM1 $\alpha$ in aberrant cellular plasticity and structural reorganization after an episode of synchronous neuronal activity pharmacologically induced in vivo [status epilepticus (SE)]. Post-SE, all animals developed spontaneous seizure events, but their frequency was dramatically increased in RIM1 $\alpha$-deficient mice $\left(R I M 1 \boldsymbol{\alpha}^{-/-}\right)$. We found that in wild-type mice $\left(R I M 1 \boldsymbol{\alpha}^{+/+}\right)$SE caused an increase in paired-pulse facilitation in the CA1 region of the hippocampus to the level observed in $R I M 1 \boldsymbol{\alpha}^{-/-}$mice before SE. In contrast, this form of short-term plasticity was not further enhanced in RIM1 $\alpha$-deficient mice after SE. Intriguingly, RIM1 $\boldsymbol{\alpha}^{-/-}$mice showed a unique pattern of selective hilar cell loss (i.e., endfolium sclerosis), which so far has not been observed in a genetic epilepsy animal model, as well as less severe astrogliosis and attenuated mossy fiber sprouting. These findings indicate that the decrease in release probability and altered short- and long-term plasticity as present in $R I M 1 \boldsymbol{\alpha}^{-1-}$ mice result in the formation of a hyperexcitable network but act in part neuroprotectively with regard to neuropathological alterations associated with epileptogenesis. In summary, our results suggest that presynaptic plasticity and proper function of RIM1 $\alpha$ play an important part in a neuron's adaptive response to aberrant electrical activity.

\section{Introduction}

The functional properties of synapses that interconnect central neurons in a dense network are key determinants of normal brain function. To ensure operation of these synapses within a physiologically appropriate dynamic range, neurons are capable of regulating their strength in response to changing electrical activity patterns (Pozo and Goda, 2010). RIM proteins are multidomain molecules that constitute an integral component of the presynaptic cytomatrix at the active zone. They represent key players in the regulation of neurotransmitter release (Schoch et al., 2006) at both excitatory and inhibitory synapses in several brain areas (Kaeser and Südhof, 2005; Mittelstaedt et al., 2010). The RIM1 gene produces two independent isoforms, RIM $1 \alpha$ and RIM1 $\beta$, that differ only in their $N$-terminal composition, with RIM $1 \beta$ lacking the $N$-terminal $\alpha$-helical Rab3 interacting domain pres-

Received Dec. 21, 2011; revised July 11, 2012; accepted July 14, 2012.

Author contributions: J.P., H.B., A.J.B., and S.S. designed research; J.P., T.O., V.B., A.W., and M.S. performed research; J.P., T.O., and M.S. analyzed data; J.P., T.O., H.B., A.J.B., and S.S. wrote the paper.

This work was supported by grants from the Deutsche Forschungsgemeinschaft (EmmyNoether Program to S.S. SFB/TR3 to H.B., S.S. and A.J.B.), the Bundesministerium fur Bildung und Forschung (NGFNplus to H.B., S.S., and A.J.B.; Unabhängige Forschergruppen in den Neurowissenschaften to S.S.), Neuron ERANET EpiNet (to H.B.), EuroEpinomics (to A.J.B.), Else Kröner Fresenius Foundation (to A.J.B.), German Israeli Foundation (to A.J.B.), and BONFOR (to S.S., H.B., and A.J.B.). We thank A. Alfter, S. Bauerkämper, M. Gerards, M. Reitze, S. Stellbogen, and E. Stüttgen for excellent technical assistance and K.M.J. van Loo for continuous support and critical discussions.

Correspondence should be addressed to Susanne Schoch, Institute of Neuropathology, Sigmund Freud Strasse 25, D-53105 Bonn, Germany. E-mail: susanne.schoch@uni-bonn.de.

DOI:10.1523/JNEUROSCI.0223-12.2012

Copyright $\odot 2012$ the authors $\quad 0270-6474 / 12 / 3212384-12 \$ 15.00 / 0$ ent in $\alpha$-RIMs (Kaeser et al., 2008a). Whereas RIM $1 \alpha$ and RIM1 $\beta$ function redundantly in the basic processes of synaptic vesicle exocytosis, RIM1 $\alpha$ is furthermore a key mediator of presynaptically expressed forms of synaptic plasticity at different CNS synapses (Castillo et al., 2002; Schoch et al., 2002; Lonart et al., 2003; Calakos et al., 2004; Fourcaudot et al., 2008; Kaeser et al., 2008a,b; Pelkey et al., 2008) (endocannabinoid-mediated long-term depression) (Chevaleyre et al., 2007). Interestingly, the amount of RIM1 present at a single synapse has been found to correlate with its activity (Jiang et al., 2010; Lazarevic et al., 2011), suggesting a potential role in the regulation of plasticity itself.

Brain disorders such as epilepsy, which are characterized by aberrant neuronal activity, engage homeostatic plasticity and substantially influence synaptic efficacy (Galvan et al., 2000; Bausch et al., 2006; Howard et al., 2007). Persistent elevation of network activity decreases the number of readily releasable synaptic vesicles and release-probability (Moulder et al., 2004, 2006; Branco et al., 2008), whereas chronic suppression of neural activity results in an increased number of docked vesicles, enlarged active zones, and an elevated frequency of mEPSCs (Murthy et al., 2001; Moulder et al., 2006; Han and Stevens, 2009). Recent evidence suggests a direct involvement of proteins involved in synaptic vesicle priming in these processes (Moulder et al., 2006). In particular, the activity-induced degradation of RIM1 has been suggested to contribute to persistent presynaptic silencing/muting (Jiang et al., 2010).

Even though the molecular mechanisms of presynaptic adaptation and plasticity have been studied in great detail, there are 
still many unanswered questions regarding their physiological role in vivo. For example, it has been postulated that presynaptic muting is neuroprotective or sets the threshold for damage during insults. To examine the role of presynaptic adaptation in vivo, we analyzed RIM1 $\alpha$ KO mice in a model of episodic brain hyperexcitability, which resembles human temporal lobe epilepsy (TLE). In this model, an episode of intense, synchronized neuronal activity, termed status epilepticus (SE), is induced in vivo by the muscarinic agonist pilocarpine. A single episode of SE then leads to chronic epilepsy, associated with the selective degeneration of hippocampal neurons (Pitsch et al., 2007). Intriguingly, RIM1 $\alpha$-deficient mice show increased spontaneous seizure activity after SE, as well as a particular hippocampal damage pattern similar to a subset of human temporal lobe epilepsy patients. Our data are consistent with the loss of a homeostatic regulatory mechanism in $R I M 1 \alpha^{-1-}$ mice.

\section{Materials and Methods}

Animals and induction of chronic epilepsy. RIM1 $\alpha^{-/-}$and RIM $2 \alpha^{-/-}$ mice were obtained and genotyped as previously described (Schoch et al., 2002 , 2006). Only male mice (age, $\geq 60 \mathrm{~d}$; weight, $>21 \mathrm{~g}$ ) were used for the analyses described below. For quantitative mRNA analysis after pilocarpine-induced SE, 60-d-old C57BL/6/N mice were used. All procedures were performed in accordance with the guidelines of the University of Bonn Medical Center Animal Care Committee. Sustained seizures were induced in experimental animals by the administration of pilocarpine using injection protocols derived from those described previously (Pitsch et al., 2007). Briefly, RIM1 $\alpha$ knock-out and corresponding wild-type littermates were injected with $335 \mathrm{mg} / \mathrm{kg}$ pilocarpine subcutaneously and their behavior was monitored at least for $2 \mathrm{~h}$ afterwards. This dose of pilocarpine was chosen because it reliably induces status epilepticus in wild-type animals while keeping mortality as low as possible. Seizures were classified as described by Pitsch et al. (2007) and Becker et al. (2008), i.e., stage III (severe seizures with rearing without falling) and stage IV (severe seizures with rearing and falling/loss of righting ability). Continuous tonic-clonic seizures (status epilepticus) were classified as stage V. Of the pilocarpine-injected animals, only those that developed SE (SE-experienced) were used for further EEG analysis, electrophysiological in vitro and in vivo examinations, and histological analyses.

Telemetric EEG monitoring and seizure classification. The electrographic features of SE and chronic seizures were analyzed with a telemetric EEG/video-monitoring system. The telemetric system (Data Science International), implantation procedure, and postoperative treatment were previously described in detail (Pitsch et al., 2007; Becker et al., 2008). To examine the features of SE, mice were implanted with EEG electrodes $7 \mathrm{~d}$ before induction of SE. To analyze the development of recurrent seizures after SE, we implanted SE-experienced mice after recovery from SE (day 7 after SE). EEG recording with a sampling rate of 1 $\mathrm{kHz}$ was started at day 9 after SE, when mice had recovered from transmitter implantation and stable EEG signals were obtained. Monitoring was performed until day 26 after SE. EEG recordings were analyzed using fast Fourier power spectral analysis. To perform a time-dependent analysis, we used a moving window approach, as described previously (Becker et al., 2008). Briefly, power was analyzed in five frequency bands: delta $(0.5-3.99 \mathrm{~Hz})$, theta $(4-7.99 \mathrm{~Hz})$, alpha $(8-12.99 \mathrm{~Hz})$, beta $(13-$ $29.99 \mathrm{~Hz})$, and gamma $(30-40 \mathrm{~Hz})$. The duration of increased EEG activity in the different frequency bands was determined as the time during which band power was increased to $>10 \%$ of maximal values. The intensity of electrographic activity during SE was quantified as the area under the band power curve for each frequency band from the initiation of continuous electrographic seizure activity until the time point of diazepam injection. The resulting values were normalized to the area under the band power curve obtained from baseline EEG recordings of identical duration obtained $24 \mathrm{~h}$ before SE. From concurrent video recordings, all spontaneous seizures in the chronic period were classified as previously described (see Animals and induction of chronic epilepsy, above) (Pitsch et al., 2007).
Table 1. Sequences of primers that were used for real-time RT-PCR

\begin{tabular}{lll}
\hline Gene & Forward (f)/ reverse primer (r) & GenBank accession number \\
\hline RIM1 $\beta$ & (f) $5^{\prime}$-CAGAAGCTGTCCCATTTTCC-3' & FJ472653 \\
& (r) $5^{\prime}$-GCTCAGAAAGCTCCAGAAGG-3' & \\
RIM2 $\alpha$ & (f) $5^{\prime}$-TCACGGAAGAGGAGAGGAAA-3' & NM_053271 \\
& (r) $5^{\prime}$-AGCACGGACTGCTCCTTCT-3' & \\
Synaptophysin & (f) $5^{\prime}$ - TTCAGGACTCAACACCTCGGT-3' & NM_009305 \\
& (r) $5^{\prime}$-CACGAACCATAGGTTGCCAAC-3' & \\
\hline
\end{tabular}

Histopathological and immunohistochemical analyses. Mice were decapitated under deep isoflurane anesthesia (Forene; Abbott) at different time points after SE as indicated. Brains were quickly removed and tissue prepared as follows. One hemisphere was fixed by cryopreservation and stored at $-80^{\circ} \mathrm{C}$ and the other hemisphere was cut into $400 \mu \mathrm{m}$ slices that were used for Timm staining or RNA analysis. For hematoxylin and eosin stains as well as immunohistochemistry, we used horizontal hippocampal cryosections $(20 \mu \mathrm{m})$. NeuN staining was done as described before (Blümcke et al., 2001; Becker et al., 2008). Neuronal densities within the pyramidal cell and dentate granule cell layers of the hippocampus were determined in at least two NeuN-stained sections per animal of the ventral hippocampus by an investigator blinded to the experimental group. All digital images were captured with a Mirax Scan and Mirax Viewer software (Carl Zeiss). Timm staining was done as previously described (Blümcke et al., 2001). After staining, we counted Timm granules in digital images captured. These counts were normalized to the corresponding area of the field of view and binned into four bins corresponding to an increasing severity of mossy fiber sprouting (bins corresponding to $0,1-10$, $10-20$, and $>20$ granules per $2500 \mu \mathrm{m}^{2}$ ) (Becker et al., 2008). For assessment of astrogliosis, a polyclonal antibody directed against glial fibrillary protein (GFAP; DAKO) was used in a dilution of 1:400. GFAP staining served as qualitative assessment of gliosis as described for human TLE (Blümcke et al., 2007). This staining was quantified in severity of $0-4(0=$ no reactive gliosis, $4=$ strong gliosis) in the whole hippocampal formation.

Real-time RT-PCR. CA1, CA3, and dentate gyrus (DG) regions were microdissected from hippocampal slices $(400 \mu \mathrm{m})$ and mRNA was isolated with a Dynabeads mRNA Direct Micro Kit (Dynal) according to the manufacturer's protocol. RIM subunit transcript quantification was performed by real-time RT-PCR (ABI PRISM 9700HT; Applied Biosystems). Synaptophysin was used as endogenous, neuron-specific reference gene because it does not show expression changes after pilocarpine-induced SE (Becker et al., 2008). Primers for RIM $2 \alpha$, RIM1 $\beta$ subunits and synaptophysin were designed with Primer3Plus software (http://www.bioinformatics.nl/cgi-bin/ primer3plus/primer3plus.cgi; Table 1). No significant homology of the amplicon sequences with other previously characterized genes has been found searching GenBank data bases by BLASTN program (PubMed, http:// blast.ncbi.nlm.nih.gov/Blast.cgi). Real-time RT-PCR was performed as described previously (Becker et al., 2008). Reactions were performed at least in triplets. The SYBR green fluorescence signal was measured in each cycle. For the mRNA quantification of RIM1 $\alpha$, we used the TaqMan gene expression assays (RIM1 $\alpha$ Mm01225731_m1) and corresponding synaptophysin (Mm01352661_m1; Life Technologies). After preincubation for 2 min at $50^{\circ} \mathrm{C}$ and $15 \mathrm{~min}$ at $95^{\circ} \mathrm{C}$, we performed $40 \mathrm{PCR}$ cycles $\left(15 \mathrm{~s}\right.$ at $95^{\circ} \mathrm{C}$ followed by $60 \mathrm{~s}$ at $60^{\circ} \mathrm{C}$ ). Specificity of the primer and primer/probe pairs was assessed using respective knock-out mice.

Relative quantification of the starting mRNA copy numbers using multiple replicates for each reaction was performed according to the $\Delta \Delta$ Ct-method (Fink et al., 1998). The signal threshold was set within the exponential phase of the reaction for determination of the threshold cycle $(\mathrm{Ct})$.

Electrophysiological recordings. Mice were decapitated under deep isoflurane anesthesia. The brain was quickly removed and immersed in icecold preparation solution of the following composition (in $\mathrm{mm}$ ): $\mathrm{NaCl} 60$, sucrose 100, $\mathrm{KCl} 2.5, \mathrm{CaCl}_{2} 1, \mathrm{MgCl}_{2} 5, \mathrm{NaH}_{2} \mathrm{PO}_{4}$ 1.25, D-glucose 20, $\mathrm{NaHCO}_{3} 26\left(\mathrm{pH} 7.4\right.$ when saturated with $\left.5 \% \mathrm{CO}_{2} / 95 \% \mathrm{O}_{2}\right)$. Depending on the experiment, either 300 - or 400 - $\mu \mathrm{m}$-thick horizontal brain slices containing the temporal part of the hippocampus were prepared with a vibratome (MicromHM650 V, Thermo Scientific). After warming the slices to $35^{\circ} \mathrm{C}$ 
in preparation solution for $20 \mathrm{~min}$, slices were kept until recording at room temperature in ACSF of the following composition (in $\mathrm{mM}$ ): $\mathrm{NaCl}$ $125, \mathrm{KCl} 3, \mathrm{CaCl}_{2} 2, \mathrm{MgCl}_{2} 2, \mathrm{NaH}_{2} \mathrm{PO}_{4} 1.25$, D-glucose $15, \mathrm{NaHCO}_{3} 26(\mathrm{pH}$ 7.4 when saturated with $5 \% \mathrm{CO}_{2} / 95 \% \mathrm{O}_{2}$ ).

To assess paired-pulse facilitation of synaptic transmission, evoked field potentials were recorded in the CA1 region of $400-\mu \mathrm{m}$-thick hippocampal slices. Those were placed in an interface-type chamber at $33 \pm$ $1^{\circ} \mathrm{C}$ and constantly superfused with ACSF at a flow rate of $2 \mathrm{ml} / \mathrm{min}$. Two ACSF-filled glass microelectrodes with tip resistance of 1-2 $M \Omega$ were positioned in stratum radiatum. Schaffer collaterals were stimulated by pairs of brief current pulses $(100 \mu$ s) delivered by a stimulus isolation unit (A365; WPI) via one of the glass microelectrodes. AC-coupled, amplified $(100 \times)$, and low-pass filtered $(3 \mathrm{kHz})$ signals were recorded via the other glass microelectrode and digitized with an InstruTECH ITC1800 data acquisition system (HEKA). Paired-pulse facilitation was quantified at different interstimulus intervals as the amplitude ratio of $\mathrm{fEPSP}_{2} / \mathrm{fEPSP}_{1}$. Experiments were controlled with AxoGraphX software (AxoGraph Scientific) run on a G4 PowerMac computer and data were analyzed using IGOR Pro software (WaveMetrics).

Miniature EPSCs and IPSCs (mEPSCs and mIPSCs, respectively) were recorded in whole-cell voltage-clamp from CA1 pyramidal neurons in 300- $\mu \mathrm{m}$-thick hippocampal slices prepared from mice 21-26 d after SE. Cells were visualized using an Eclipse FN1 upright microscope equipped with infrared difference interference contrast optics and a water-immersion lens $(\times 60,1.0 \mathrm{NA}$; Nikon). Somatic whole-cell voltage-clamp recordings were made with an AxoPatch $200 \mathrm{~B}$ amplifier (Molecular Devices). Data were sampled at $10 \mathrm{kHz}$ and filtered at $1 \mathrm{kHz}$ with a Digidata 1322A interface controlled by pClamp software (Molecular Devices). Electrode resistance in the bath ranged from 3 to $5 \mathrm{M} \Omega$, and series resistance ranged from 8 to $27 \mathrm{M} \Omega$. The internal solution contained the following (in $\mathrm{mm}$ ): cesiummethanesulfonate 110, tetraethylammonium chloride 10, 4-(2-hydroxyethyl)-1-piperazineethanesulfonic acid 10, ethylenglycole-bis(2-aminoethylether)-N,N, $\mathrm{N}^{\prime}, \mathrm{N}^{\prime}$ tetraacetic acid 11, $\mathrm{CaCl}_{2}$ 2, Mg-ATP 2 (pH adjusted to 7.2 with $\mathrm{CsOH}, 290$ $\mathrm{mOsmol}$ ). The extracellular ACSF was identical to that used for slice storage and field potential recording $\left(32^{\circ} \mathrm{C}\right)$. Holding potential was corrected offline for a liquid junction potential of $10 \mathrm{mV}$.

Electrophysiological analysis. Offline detection and analysis of mEPSCs and mIPSCs was performed with a custom routine programmed in IGOR Pro. Detection of mEPSC events was performed by calculating the first derivative of current traces and selecting events for which the first derivative was larger than $5 \times$ the standard deviation of the current recording. Events were accepted for further analysis if their amplitude exceeded $5 \times$ the standard deviation of the pre-event baseline $(3 \mathrm{~ms})$. Furthermore, the time constant with which events decayed assessed with a monoexponential fit had to be within a range of 5 to $15 \mathrm{~ms}$. mIPSCs were detected with two adjacent moving windows $(0.5 \mathrm{~ms}$ duration each), with difference threshold between the mean current amplitudes in the two windows set to $5 \mathrm{pA}$. All detected postsynaptic currents were assessed by visual inspection and events due to spurious noise were rejected manually.

Statistics. The $\chi^{2}$ test was used for statistical assessment of phenotypic differences between strains. Group comparisons were performed using the unpaired Student's $t$ test or a Mann-Whitney $U$ test. Comparisons between more than two groups were performed with a two-way ANOVA followed by Bonferroni's posttest where appropriate. The values were considered significantly different when $p<0.05$. Results were expressed as mean \pm SEM.

\section{Results}

Altered short-term plasticity in adult $R I M 1 \alpha^{-/-}$mice

Analyses of cultured hippocampal neurons and acute slices prepared from juvenile (3-8 weeks old) mice deficient for RIM1 $\alpha$ have revealed alterations in basic synaptic transmission, e.g., a reduction in release probability and in certain forms of short-and long-term synaptic plasticity, whereas deletion of RIM $2 \alpha$ alone did not result in any changes (Kaeser and Südhof, 2005; Mittel- staedt et al., 2010). To test whether this phenotype is affected by the maturation of the synaptic network, we measured pairedpulse facilitation (PPF) in the CA1 region of the hippocampus in acute slices from brains of adult mice (3-4 months old). RIM1 $\alpha$ deficient hippocampal slices showed an increase in PPF ( fEPSP $_{2} /$ fEPSP $_{1}$ ) compared with wild-type littermate controls (Fig. $1 A$, right, $n=5$ for each group). Representative PPF signal in both strains is shown in Figure $1 A$, left. This finding indicates that release probability is reduced, similar to previous finding in younger animals.

We then examined whether RIM $1 \alpha$-deficient mice show signs of altered neuronal excitability. To this end, we implanted electrodes for telemetric EEG recording and obtained a prolonged period of baseline cortical EEG recording (representative EEG: baseline EEG 5 min after pilocarpine injection and during SE; Fig. $1 D$, left). We could not observe any signs of hyperexcitability or spontaneous seizure activity in these animals. Furthermore, no differences were detected in baseline EEG recordings between $R I M 1 \alpha^{+/+}$and $R I M 1 \alpha^{-/-}$mice regarding the relative amplitude strength (Student's $t$ test: alpha band, $p=0.66$; beta band, $p=$ 0.10 ; gamma band, $p=0.44$; delta band, $p=0.31$, theta band, $p=$ 0.38 ; Fig. $1 B$ ). These results indicate that despite the marked disturbance in synaptic release dynamics, the excitability of the neuronal network as a whole is not strongly affected.

\section{Acute response of $R I M 1 \alpha^{-/-}$mice to pilocarpine-induced status epilepticus}

We next asked how RIM1 $\alpha^{+/+}$and $R I M 1 \alpha^{-/-}$mice respond in vivo to an episode of strong electrical activity. Therefore, we subjected RIM $1 \alpha$-deficient mice and wild-type littermates to SE induced by systemic administration of the muscarinic agonist pilocarpine. To test whether the severity of pilocarpine-induced SE was similar in $R I M 1 \alpha^{+/+}$and $R I M 1 \alpha^{-/-}$mice, we implanted electrodes for telemetric recording at least 1 week before SE was induced and examined the EEG changes after pilocarpine injection (for a representative EEG recording of a $R I M 1 \alpha^{+/+}$and a $R I M 1 \alpha^{-/-}$mouse before and during SE, see Fig. $\left.1 D\right)$. Approximately $40 \mathrm{~min}$ after injection, mice from both groups experienced SE, defined as a period of continuous tonic-clonic seizures without individual separable seizure events. SE was characterized by an increase in the band power in the alpha range, shown in representative $R I M 1 \alpha^{+/+}$and $R I M 1 \alpha^{-/-}$mice for the band power in the alpha range (Fig. $1 C$, time point zero corresponds to the time of pilocarpine injection, stage III/IV seizures are marked with asterisks, and onset of SE is indicated by arrows; representative EEG examples shown in Fig. $1 D$ taken at the time points indicated by dots in Fig. 1C). Significant changes in electrographic activity after SE were detected in the alpha, beta, and delta frequency bands (Fig. $1 E$ ). However, there was no significant difference with respect to the relative change in band power of cortical EEG during SE between both strains. In addition, we could find no differences between $R I M 1 \alpha^{-1-}$ mice and littermate controls in the duration of SE, quantified as the time during which band power was increased to $>10 \%$ of maximal values (e.g., alpha band $R I M 1 \alpha^{+/+} 42.1 \mathrm{~min} \pm 2.9, R I M 1 \alpha^{-/-} 48.5 \pm$ 2.8 , Student's $t$ test $p=0.4$; data not shown).

Because RIM $1 \alpha$ and RIM $2 \alpha$ exhibit a complex pattern of redundancy, depending on the type of synapse being analyzed, and because RIM $2 \alpha$ is strongly expressed in the dentate gyrus (Schoch et al., 2006), we also included RIM $2 \alpha^{-/-}$mice in our subsequent analyses. As a further test for the susceptibility of the $\alpha$-RIM-deficient mice to pilocarpine-induced seizures, we examined the response of the animals after pilocarpine injec- 

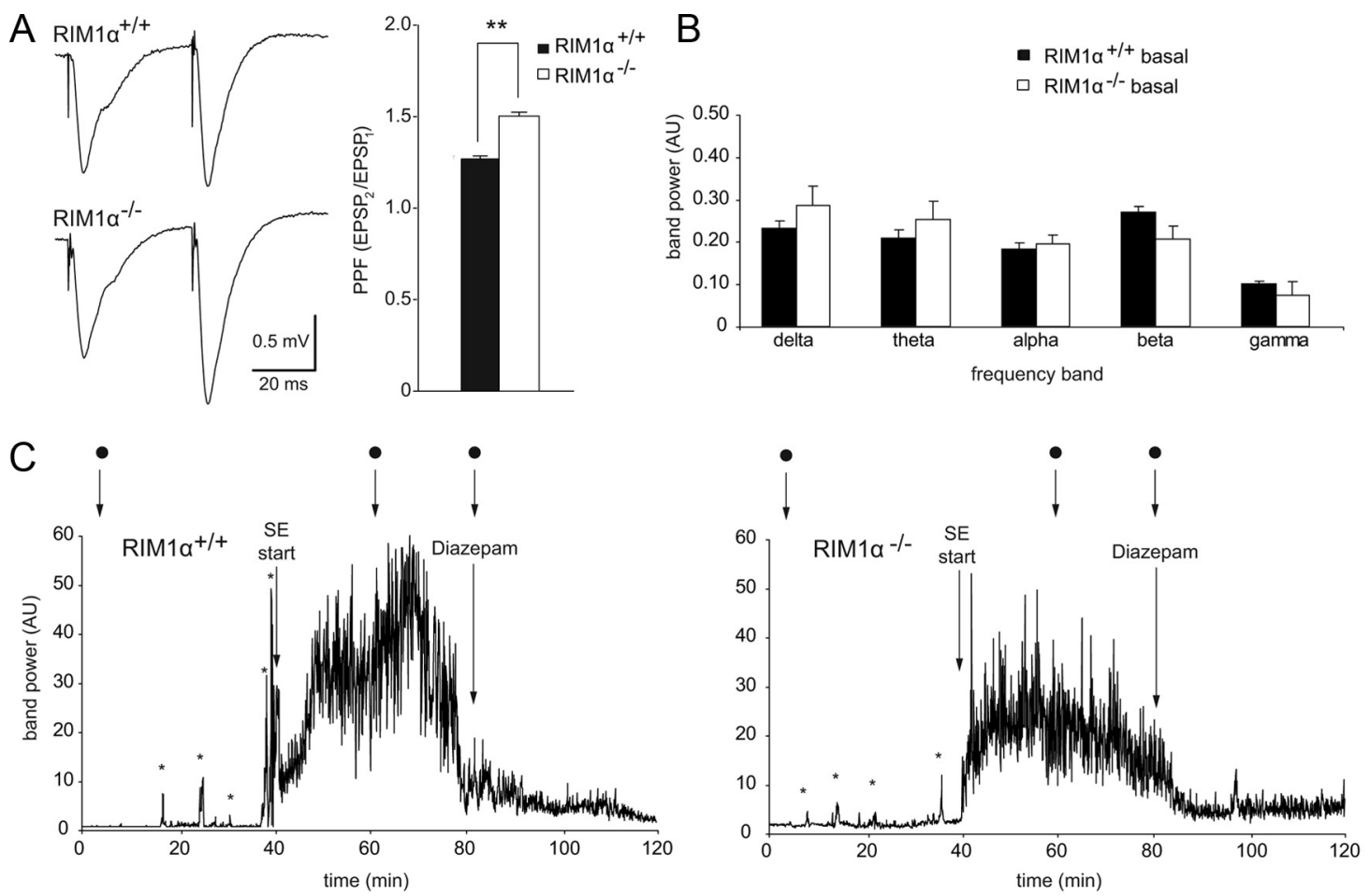

$\mathrm{D}$

E
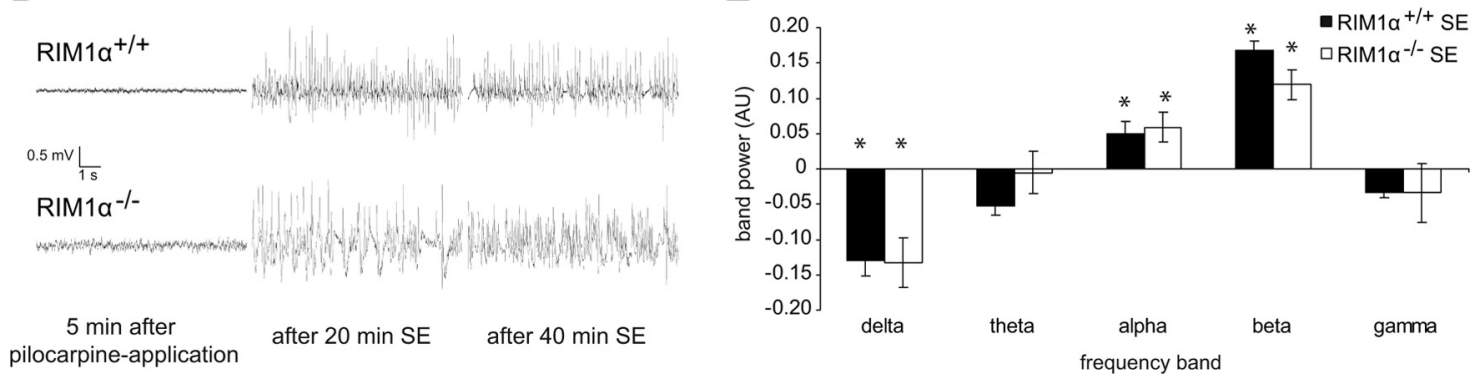

Figure 1. Adult $R I M 1 \alpha^{-1-}$ mice exhibit altered short-term plasticity but no abnormalities in basal or pathophysiological electrographic activity. A, Adult RIM1 $\alpha^{-1-}$ mice show an increase in PPF in the CA1 region of the hippocampus. Facilitation was assessed by dividing the magnitude of the second of two closely spaced EPSPs by the first EPSP $(n=5$ for each group ${ }^{* *} p<0.01$, Mann-Whitney $U$ test). $B$, No differences were observed in baseline EEG recordings between $R I M 1 \alpha^{+/+}(n=6)$ and $R I M 1 \alpha^{-/-}(n=5)$ mice regarding the relative amplitude strength (Student's $t$ test: alpha band, $p=0.66$; beta band, $p=0.10$; gamma band, $p=0.44$; delta band, $p=0.31$; theta band, $p=0.38$ ). C, EEG recordings before and during pilocarpine-induced SE were subjected to Fourier transformation and the power in different frequency bands was analyzed in $R I M 1 \alpha^{+/+}$and $R I M 1 \alpha^{-/-}$mice (left and right, respectively; animals identical to those shown in $\boldsymbol{D}$ ). Representative analyses of band power in the alpha band are shown. The zero time point corresponds to the time of pilocarpine injection. Asterisks mark isolated behavioral seizures (at least stage III; see Materials and Methods) before animals entered continuous SE (see Materials and Methods). Dots mark the time points of the EEG recordings shown in $\boldsymbol{D}$. Diazepam was administered to terminate $S E$, as indicated. $\boldsymbol{D}$, Representative EEG recordings 5 min after pilocarpine application (when no signs of seizures are observed) and 20 and 40 min after the start of SE for one representative $R I M 1 \alpha^{+/+}$and $R I M 1 \alpha^{-/-}$mouse. E, The intensity of electrographic activity during SE was quantified as the area under the band power curve for each frequency band from the initiation of continuous electrographic seizure activity until the time point of diazepam injection. The resultant values were normalized to the area under the band power curve obtained from baseline EEG recordings of identical duration obtained $24 \mathrm{~h}$ before SE. Compared to basal cortical EEG significant changes during SE were found in the delta, alpha, and beta frequency bands with respect to the relative increase. However, no difference between $R I M 1 \alpha^{+/+}$and $R I M 1 \alpha^{-/-}$mice was detected by analyzing EEG power in different frequency bands. AU, Arbitrary units. Error bars indicate SEM.

tion. To this end, the mice were either categorized as sham without seizures, sham with at least one stage III seizure, died before reaching SE, experienced SE, or died during SE (Fig. $2 A, B)$. The percentage of animals experiencing SE was similar between the respective $\operatorname{RIM} 1 \alpha$ and $\operatorname{RIM} 2 \alpha$ wild-type and knock-out animals. However, we observed differences with regard to mortality. Whereas no RIM1 $\alpha^{-1-}$ mice died before reaching SE, the mortality during SE was slightly increased in RIM1 $\alpha^{-1-}$ (Fig. $2 A$ ). Also the RIM $2 \alpha^{-1-}$ animals exhibited a significantly lower mortality before reaching SE and an increased mortality during SE (Fig. $2 B$ ). Together, compared with their wild-type littermates, both $R I M 1 \alpha^{-/-}$and $R I M 2 \alpha^{-/-}$show a significantly different response to pilocarpine-induced sei- zures $\left(R I M 1 \alpha^{+/+}, n=81 ; R I M 1 \alpha^{-/-}, n=54 ; \chi^{2}\right.$ test, $p<$ $0.001 ; R I M 2 \alpha^{+/+}, n=33 ; R I M 2 \alpha^{-/-}, n=34 ; \chi^{2}$ test, $p<$ $0.001)$.

Next, we examined several parameters relevant to the acute phase using only the data of the group that experienced and survived SE. Whereas the latency to generalized seizure onset was significantly shorter in RIM1 $\alpha^{-/-}$compared with $R I M 1 \alpha^{+/+}$ mice (Fig. $2 C$, left), RIM $2 \alpha^{-/-}$mice did not exhibit an altered latency to the first seizure after pilocarpine injection (Fig. $2 D$, left). Neither $R I M 1 \alpha^{-/-}$nor $R I M 2 \alpha^{-/-}$animals showed significant changes regarding the latency to the start of SE (Fig. 2C,D, right) or in seizure frequency and severity during the acute stage (Table 2). 
In summary, these results indicate that the intensity of electrographic seizure activity experienced after pilocarpine injection is not affected by the ablation of RIM $1 \alpha$ or RIM $2 \alpha$. However, in the absence of RIM1 $\alpha$, the susceptibility to the onset of the first pilocarpine-induced seizure is reduced.

Development of chronic seizures is strongly increased in RIM1 $\alpha^{-/-}$mice Having determined the immediate response of the network to a convulsant, we asked whether the long-term consequences of an episode of SE are altered by deletion of RIM $1 \alpha$. To determine the frequency and severity of spontaneous epileptic seizures after SE, we performed long-term telemetric EEG/video-monitoring in wild-type $\left(R I M 1 \alpha^{+/+} / R I M 2 \alpha^{+/}\right.$ +), $R I M 1 \alpha^{-/-}$, and RIM $2 \alpha^{-/-}$mice 9 to $28 \mathrm{~d}$ after SE (for representative examples of EEG from control animals before SE and interictal EEG in SE-experienced animals, see Fig. $3 A$ ).

We observed spontaneous seizures in all SE-experienced $R I M 1 \alpha^{+/+}$mice $(n=$ 14 ) and $R I M 1 \alpha^{-/-}$mice ( $n=6$; for representative EEG recordings of seizures in all analyzed genotypes, see Fig. 3B). However, spontaneous stage III/IV seizures were much more frequent in $R I M 1 \alpha^{-1-}$ mice compared with $R I M 1 \alpha^{+/+}$(Fig. $3 C$, left). When considering spontaneous stage III and IV seizures separately, the ratio was shifted toward stage III seizures in SE-experienced $R I M 1 \alpha^{-1-}$ mice (group comparison $\chi^{2}$ test $p<0.001$; Fig. $3 C$, right). The duration of individual seizure episodes (Fig. 3D, left) was significantly reduced in chronic stage III seizures, but not different in stage IV seizures. The average amplitude of the EEG activity during the seizures (Fig. 3D, right), was not significantly different when comparing SE-experienced $R I M 1 \alpha^{+/+}$and $R I M 1 \alpha^{-/-}$mice. Spontaneous seizures also occurred in all SE-experienced $R I M 2 \alpha^{-1-}$ mice $(n=9)$ and wild-type littermates $(n=8)$. However, in accordance with the lack of a synaptic phenotype in the $R I M 2 \alpha^{-/-}$mice, the properties of the individual seizure episodes and the development of chronic epilepsy was unaltered in the $R I M 2 \alpha^{-/-}$mice compared with RIM $2 \alpha^{+/+}$littermates (Fig. $3 E$ ). Thus, deletion of RIM $1 \alpha$, but not RIM $2 \alpha$, resulted in a dramatic increase in the number of chronic seizures, but the severity of the seizures was lower.

Following SE, RIM1 $\alpha$-deficient mice exhibit a distinct neuropathological structural reorganization corresponding to endfolium sclerosis

Epileptogenesis goes along with fundamental neuropathological alterations in the hippocampal formation, in particular segmental neuronal cell loss and axonal reorganization. The changes observed in animal models after induced SE resemble those described in human TLE with mesial temporal sclerosis (Wyler et al., 1992; Blümcke et al., 1999; Wieser, 2004). In native conditions, genetic deletion of either RIM1 $\alpha^{-/-}$or RIM $2 \alpha^{-/-}$did not
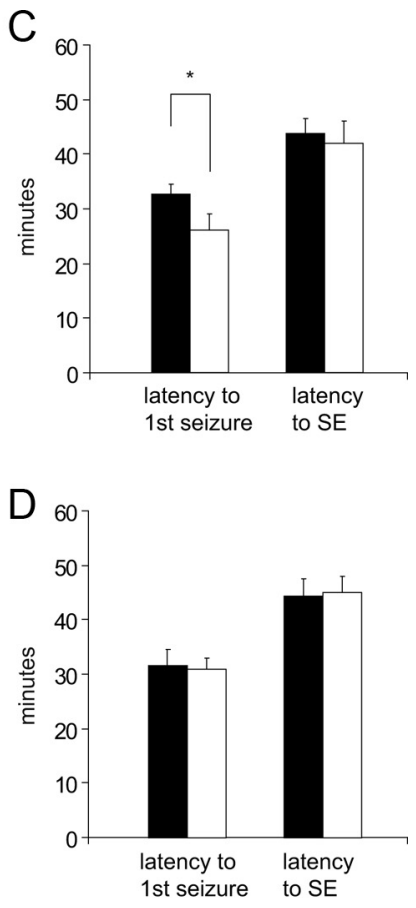

Figure 2. Susceptibility to pilocarpine-induced seizures in $R I M 1 \alpha^{-/-}$and $R I M 2 \alpha^{-/-}$animals. $A, B$, Behavioral classification SE (died before SE) and during SE was quantified. The group of animals experiencing SE was similar in both RIM1 $\alpha$ and RIM $2 \alpha$ groups. However, both RIM1 $\alpha^{-}$and $R I M 2 \alpha^{-}$showed less mortality in the acute phase but an increase during SE. Distribu$n=33 ; R I M 2 \alpha^{-/-}, n=34 ; *{ }^{* *} p<0.001, \chi^{2}$ test). C, The latency to generalized seizure onset, defined as the first seizure, was significantly shorter in $R I M 1 \alpha^{-/-}$compared with $R I M 1 \alpha^{+/+}$mice $\left(26 \pm 3\right.$ min in $R I M 1 \alpha^{-/-}$vs $33 \pm 2$ min in $R I M 1 \alpha^{+/+}$; ${ }^{*} p<0.05$, Mann-Whitney $U$ test). $\boldsymbol{D}$, In contrast, no significant changes were observed regarding seizure onset in $R I M 2 \alpha^{-1-}$ mice $\left(31 \pm 2 \mathrm{~min}\right.$ in $R I M 2 \alpha^{-/-}$vs $32 \pm 3 \mathrm{~min}$ in $\left.R I M 2 \alpha^{+/+}\right)$. C, D, Both strains did not show differences in the latency to the onset of status epilepticus. Error bars indicate mean \pm SEM.

Table 2. Seizure severity and frequency during the acute stage after pilocarpine injection

\begin{tabular}{|c|c|c|c|}
\hline \multirow[b]{2}{*}{ Genotype } & \multicolumn{2}{|c|}{ Seizure severity } & \multirow[b]{2}{*}{ Seizure frequency (mean $\pm S D$ ) } \\
\hline & Stage III & Stage IV & \\
\hline$R I M 1 \alpha^{+/+}(n=29)$ & $25 \%$ & $75 \%$ & $3.1 \pm 0.1$ \\
\hline$R I M 1 \alpha^{-/-}(n=23)$ & $31 \%$ & $69 \%$ & $3.2 \pm 0.1$ \\
\hline$R I M 2 \alpha^{+/+}(n=21)$ & $43 \%$ & $57 \%$ & $3.1 \pm 0.2$ \\
\hline$R I M 2 \alpha^{-1-}(n=21)$ & $44 \%$ & $56 \%$ & $3.9 \pm 0.3$ \\
\hline
\end{tabular}

reveal obvious neuropathological changes in the hippocampal formation (for representative hippocampal slices of RIM $1 \alpha$ mice, see Fig. $4 C$, left; RIM $2 \alpha$ data not shown). To address structural alterations after induction of SE, we performed a detailed neuropathological analysis at the stage of chronic recurrent seizure activity.

$R I M 1 \alpha^{+/+}$mice showed a pronounced segmental neuronal damage of $70 \%$ in the CA3 after SE (Student's $t$ test, $p<0.05$ ) and of $55 \%$ in CA1 region (Student's $t$ test, $p<0.01$; Fig. $4 A$ ), while the cell numbers in the dentate gyrus (Student's $t$ test, $p=0.16$ ) and the hilar regions were not significantly altered (Student's $t$ test, $p=0.39$ ). This pattern generally reflects the classical hippocampal sclerosis of type Ia according to Blümcke and colleagues (2007) (both $R I M 1 \alpha^{+/+}$groups, $n=5$; Fig. $4 C$, top right). In contrast, $R I M 1 \alpha^{-/-}$mice revealed substantial neuronal 
A
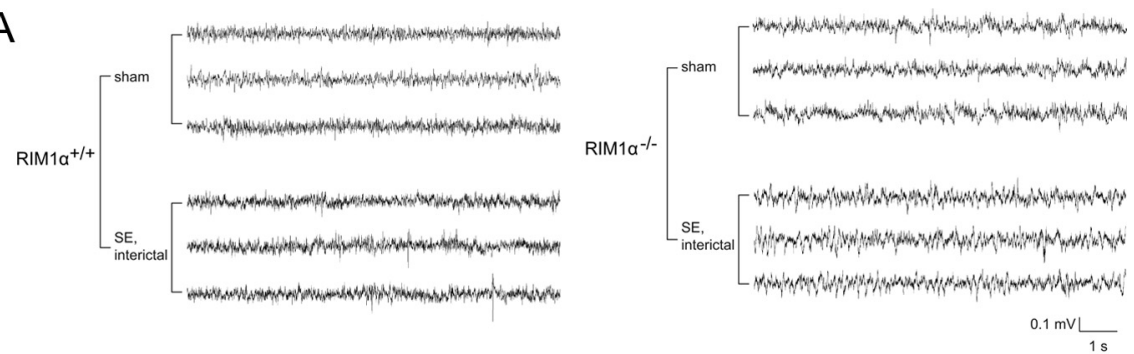

B
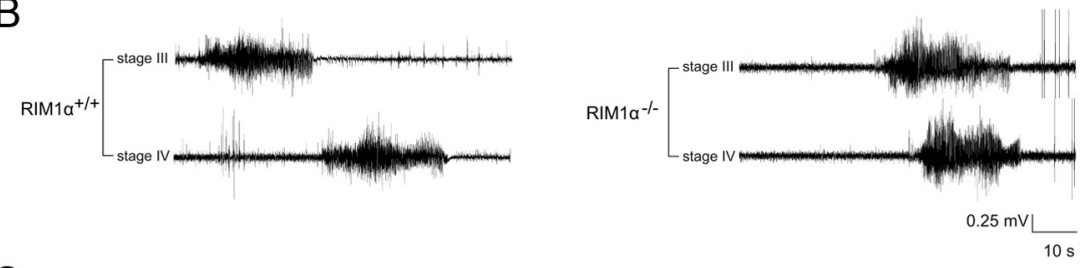

C

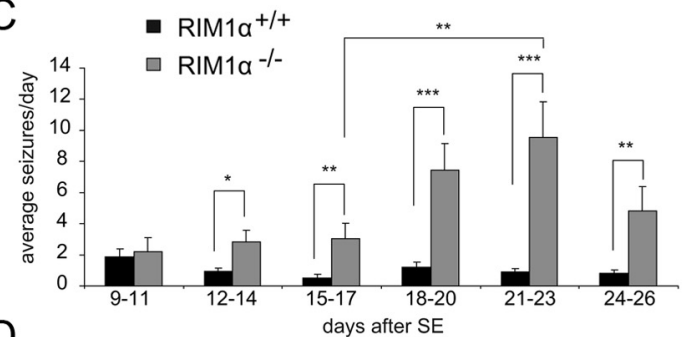

D
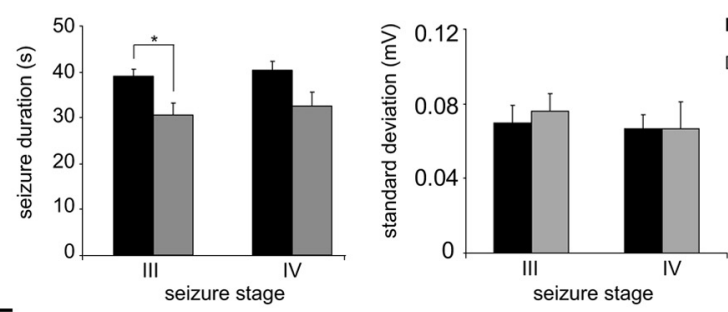

$\mathrm{E}$
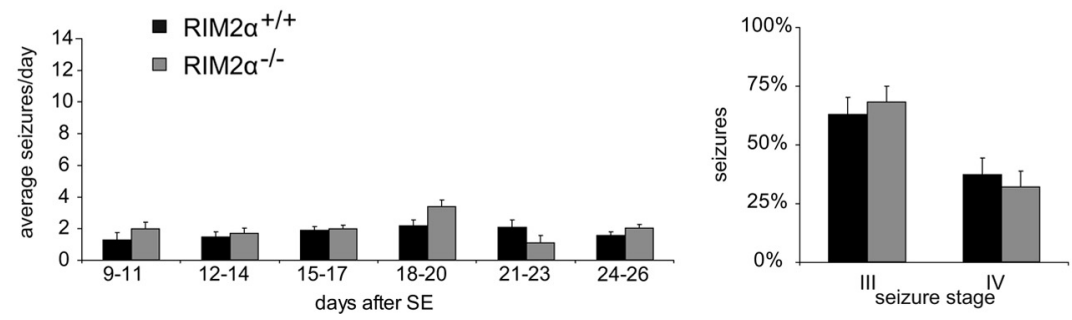

Figure 3. Development of chronic seizures is strongly increased in $R I M 1 \alpha^{-/-}$mice. $\boldsymbol{A}$, Representative interictal EEG recordings from control and SE-experienced $R I M 1 \alpha^{+/+}$and $R I M 1 \alpha^{-/-}$mice, as indicated. Recordings were $>11 \mathrm{~d}$ after treatment. $\boldsymbol{B}$, Representative EEG recordings during stage III (top traces) and stage IV seizures (bottom traces) in RIM1 $\alpha^{+/+}$and $R I M 1 \alpha^{-/-}$ mice. $C$, Left, Development of spontaneous seizure activity after SE in $R I M 1 \alpha^{+/+}$versus $R I M 1 \alpha^{-/-}$mice. Seizures were quantified in intervals of 3 consecutive days, and the average seizure frequency per day is presented as "average seizures/day." The frequency of spontaneous seizures is substantially increased in $R I M 1 \alpha^{-/-}$versus $R I M 1 \alpha^{+/+}$mice $\left({ }^{*} p<0.05\right.$, ${ }^{* *} p<0.01$, ${ }^{* * *} p<0.001$, Mann-Whitney $U$ test). Seizures were more severe in SE-experienced $R I M 1 \alpha^{+/+}$mice, with a higher fraction of generalized stage IV seizures. $C$, Right, ${ }^{* * *} p<0.001, \chi^{2}$ test. D, RIM1 $\alpha^{-/-}$revealed shorter stage III seizures in the chronic period, whereas stage IV seizures did not differ regarding seizure duration $\left({ }^{*} p<0.05\right.$, Student's $t$ test). No significant differences with respect to seizure variance (right) were found between $R I M 1 \alpha^{-1-}$ and $R I M 1 \alpha^{+/+}$mice. $\boldsymbol{E}$, In contrast, no significant differences regarding frequency (left) or severity (right) were found in $R I M 2 \alpha^{-/-}$mice compared with $R I M 2 \alpha^{+/+}$mice after SE. In $\boldsymbol{C}-\boldsymbol{E}, n=6$ for $R I M 1 \alpha^{-/-}$and $n=14$ for $R I M 1 \alpha^{+/+} ; n=9$ for $R I M 2 \alpha^{-/-}$and $n=8$ for $R I M 2 \alpha^{+/+}$. Error bars indicate mean \pm SEM.

cell loss in the CA3 (29\%; Student's $t$ test, $p<0.001)$ as well as the hilar region (39\%; Student's $t$ test, $p<0.05)$, but not in the CA1 area (Student's $t$ test, $p=0.38$; Fig. $4 B$, Fig. $4 C$, bottom right). RIM1 $\alpha$ deficiency causes granule cell dispersion and cell loss of $33 \%$ in the dentate gyrus after SE (Student's $t$ test, $p<0.05$; RIM1 $\alpha^{-1-}$ control, $n=5$; RIM1 $\alpha^{-/-} \mathrm{SE}, n=6$; Fig. $4 C$, bottom right, inset). These neuropathological alterations resemble the pattern of endfolium sclerosis/mesial temporal sclerosis type 3 , as observed in biopsy specimens of patients with pharmacoresistant TLE (Fig. 4G, left) (Blümcke et al., 2007). To the best of our knowledge, the hippocampal lesion pattern of endfolium sclerosis has not been described in animal models of epilepsy before. This strain of mice apparently has a particularly low resistance against seizure-induced neuronal degeneration in the dentate gyrus and hilar area. Our data suggest RIM1 $\alpha$ represents a factor that protects neurons of the hilar areas as well as dentate gyrus granule cells from degeneration.

A second neuropathological hallmark of Ammon's horn sclerosis is reactive astrogliosis, which is also seen in hippocampi from human with TLE (Fig. $4 G$, right). After immunolabelings with the glial-specific marker protein GFAP, animals were grouped into categories depending on their staining intensity in the whole hippocampal formation (stratum moleculare, radiatum, oriens, and hilar region). Whereas almost $50 \%$ of wild-type animals after SE showed strong astrogliosis (category 4 ), $>75 \%$ of $R I M 1 \alpha^{-/-}$mice fell into the group of mild astrogliosis (category 2) and none were labeled as category 4 ( $\chi^{2}$ test, $p<0.001$, same animals as for cell count were used; Fig. $4 D$ ), indicating that $R I M 1 \alpha^{-/-}$animals exhibit a less severe reactive astrogliosis.

\section{Mossy fiber sprouting is substantially attenuated in RIM1 $\alpha^{-/-}$mice}

A major phenomenon of structural reorganization in experimental and human TLE is the sprouting of mossy fibers into the supragranular layer of the dentate gyrus monitored by Timm staining (Houser, 1992; Cavazos et al., 2003). A prominent staining was seen $28 \mathrm{~d}$ after SE in $R I M 1 \alpha^{+/+}$animals (Fig. $4 E$, top right). In contrast, mossy fiber sprouting after SE was strongly reduced in RIMI $\alpha^{-/-}$compared with $R I M 1 \alpha^{+/+}$mice (Fig. $4 E$, bottom right). A semiquantitative analysis of Timm granules in the inner molecular layer according to a quantification system (Becker et al., 2008) confirmed these results $\left(R I M 1 \alpha^{+/+}\right.$control, $n=10$; RIM1 $\alpha^{+/+}$SE, $n=11 ; R I M 1 \alpha^{-/-}$control, $n=6$; RIM1 $\alpha^{-1-}$ SE, $n=5$; Fig. $\left.4 F\right)$.

We observed a significant increase in supragranular Timm staining in RIM1 $\alpha^{+/+}$mice at later stages $\left(\chi^{2}\right.$ test, $p<0.001$; Fig. $4 F$, black bars), whereas this increase was strongly reduced in $R I M 1 \alpha^{-1-}$ mice (Fig. 4F, gray bars). In all control animals, the molecular layer of the dentate gyrus was completely devoid of Timm staining. These results show that mossy fibers deficient for RIM1 $\alpha$ exhibit less SE-induced sprouting. 
A

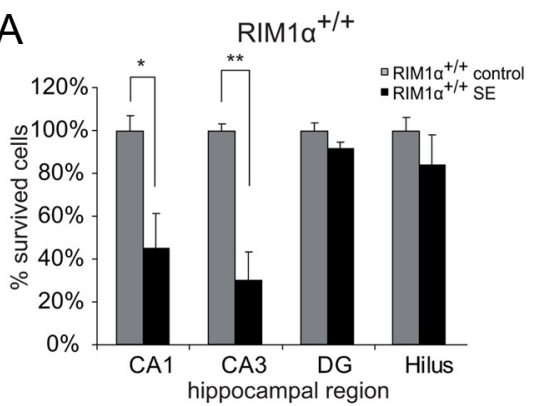

C

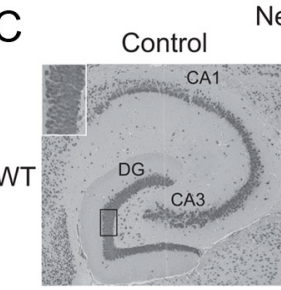

NeuN
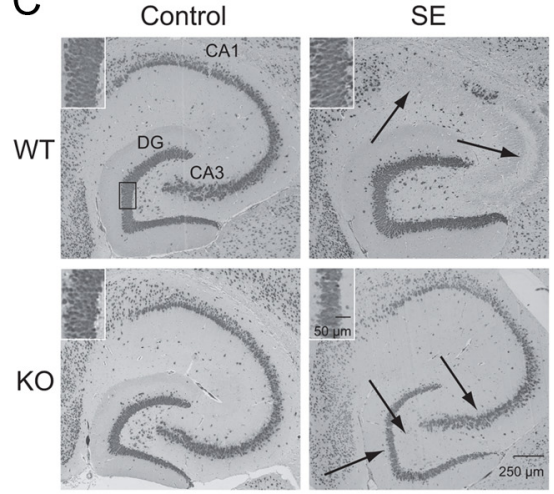

$\mathrm{E}$

Control

TIMM

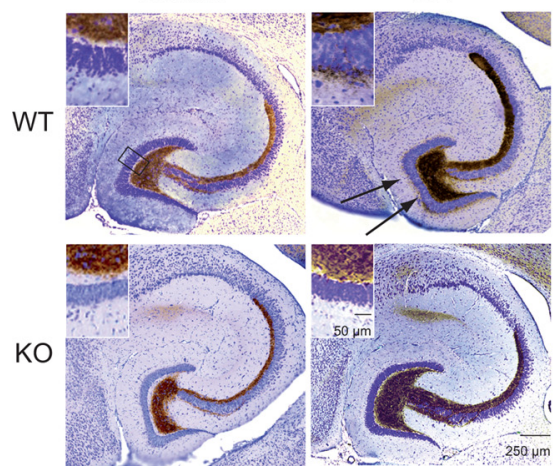

B

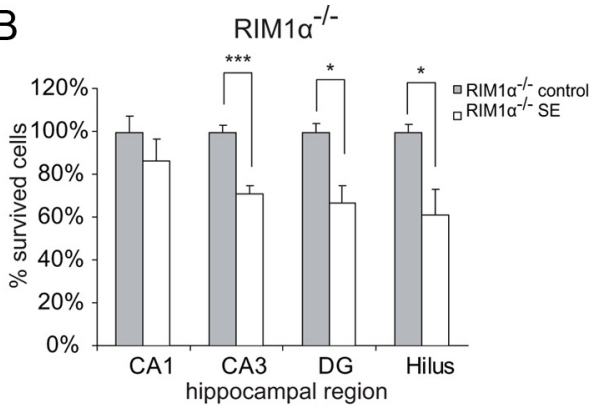

D GFAP

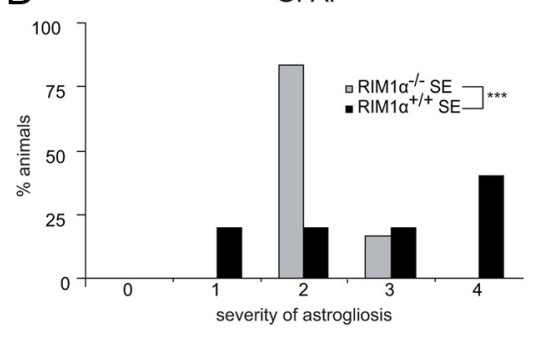

$\mathrm{F}$

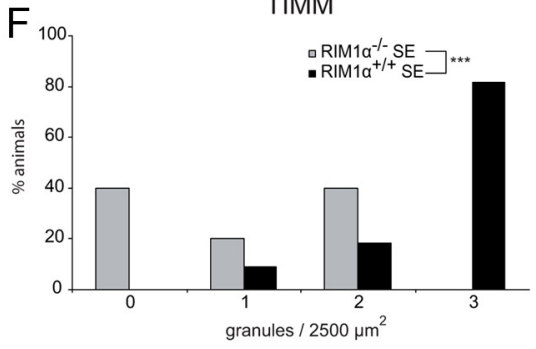

G

NeuN

GFAP

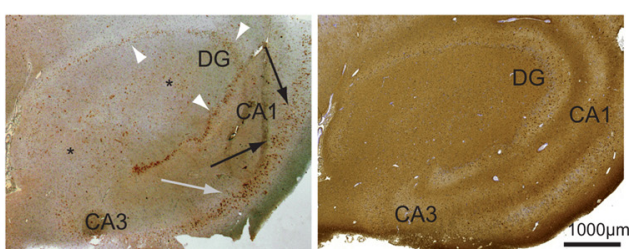

Figure 4. $R I M 1 \alpha^{-1-}$ mice show an endfolium sclerosis as well as a decrease in astrogliosis and mossy fiber sprouting in the chronic period. $A, R I M 1 \alpha^{-1-}$ mice revealed substantial neuronal cell loss restricted to the areas CA3 (RIM1 $\alpha^{-1-}$ control, 25.6 cells $/ 10,000 \mu \mathrm{m}^{2} ; R I M 1 \alpha^{-1-}$ after SE, 18.3 cells $/ 10,000 \mu \mathrm{m}^{2} ; * * 0<0.01$, Student's t test), dentate gyrus (RIM1 $\alpha^{-1-}$ control, 98.7 cells $/ 10,000 \mu \mathrm{m}^{2} ; R I M 1 \alpha^{-/-}$after SE, 65.9 cells $/ 10,000 \mu \mathrm{m}^{2} ;{ }^{*} p<0.05$, Student's t test) and the hilar region of the hippocampus (RIM1 $\alpha^{-/-}$control, 3.1 cells $/ 10,000 \mu \mathrm{m}^{2} ; R I M 1 \alpha^{-/-}$after $\mathrm{SE}, 1.9$ cells $/ 10,000 \mu \mathrm{m}^{2} ;{ }^{*} p<0.05$, Student's $t$ test), which resembles a lesion of so-called endfolium sclerosis. $\boldsymbol{B}$, In contrast, $R I M 1 \alpha^{+/+}$showed a classical hippocampal sclerosis, which is characterized by pronounced segmental neuronal damage in CA3 (RIM1 $\alpha^{+/+}$control, 24.1 cells $/ 10,000 \mu \mathrm{m}^{2} ; R I M 1 \alpha^{+/+}$after SE, 7.2 cells $/ 10,000 \mu \mathrm{m}^{2} ;{ }^{*} p<0.05$, Student's $t$ test) and CA1 $\left(\right.$ RIM $1 \alpha^{+/+}$control, 38.4 cells $/ 10,000 \mu \mathrm{m}^{2} ;$ RIM1 $\alpha^{+/+}$after SE, 17.3 cells $/ 10,000 \mu \mathrm{m}^{2} ;{ }^{* * *} p<0.01$, Student's $t$ test), which reflects the classical pattern of Ammon's horn aclerosis. C, Representative hippocampal sections stained with an antibody directed against NeuN. Note the specific neuronal cell loss in areas CA3, DG, and hilus after SE in $R I M 1 \alpha^{-/}$mice (endfolium sclerosis) but not a classical Ammon's horn sclerosis in RIM1 $\alpha^{+/+}$mice (CA1 and CA3). Arrows point to regions with cell loss, which is quantified in Figure 4, $A$ and $B$. RIM1 $\alpha$ deficiency causes granule cell dispersion in the dentate gyrus after SE (bottom right, inset), which is absent in corresponding littermate controls (top right, inset). $D$, Assessment of the severity of astrogliosis with a semiquantitative measure in animals after SE. RIM1 $\alpha^{-/-}$animals revealed less severe reactive astrogliosis $\left(\chi^{2}\right.$ test, $\left.{ }^{* * *} p<0.001\right)$. E, Mossy fiber sprouting is visualized by Timm staining. SE-experienced $R I M 1 \alpha^{+/+}$mice display mossy fiber sprouting with an increased density of Timm-stained terminals in the supragranular layer after SE (top right), whereas control mice did not (top left). In contrast, SE-induced mossy fiber sprouting is virtually absent in SE-experienced $R I M 1 \alpha^{-1-}$ mice (bottom right). $\boldsymbol{F}$, Assessment of the severity of mossy fiber sprouting with a semiquantitative measure in animals after SE. Mossy fiber sprouting is strongly reduced in $R I M 1 \alpha^{-1-}$ mice ${ }^{* * *} p<0.001, \chi^{2}$ test). G, Representative hippocampal sections from a patient with TLE with the pattern of endfolium sclerosis stained with antibodies against NeuN (left) and GFAP (right). Asterisks depict the areas of the hilar region/CA4 and CA3 that show the characteristic Ammon's horn sclerosisassociated neuronal cell loss. A significant reduction of granule cells is also present in the dentate gyrus (white arrowheads). However, significant neuronal cell loss is not present in areas CA2 (gray arrow) and CA1 (black arrows). This neuronal cell loss pattern fulfils the criteria of endfolium sclerosis. Correspondingly, the representative GFAP immunohistochemistry demonstrates a pronounced fibrillary astrogliosis in the hilar region/CA4 and CA3 (asterisks), whereas more subtle combined fibrillary and cellular astrogliosis is present in the other hippocampal subfields. In $A$ and $B, n=5$ for all groups. Error bars indicate mean \pm SEM. In $C, n=10$ for $R I M 1 \alpha^{+/+}$control and $n=11$ for $R I M 1 \alpha^{+/+}$SE; $n=6$ for RIM1 $\alpha^{-/-}$control and $n=5$ for $R I M 1 \alpha^{-/-}$SE.

\section{SE-induced changes of presynaptic function in $R I M 1 \alpha^{-/-}$ versus $R I M 1 \alpha^{+/+}$mice}

We had confirmed an increased PPF indicative of decreased release probability in $R I M 1 \alpha^{-/-}$mice (Fig. $1 A$ ) (Schoch et al., 2002; Calakos et al., 2004). We now examined how this form of presynaptic short-term plasticity is altered by SE in both groups of mice. We found that SE caused a significant increase in PPF over a range of interstimulus intervals in wild-type mice (oneway ANOVA with Dunnett's posttest, $p<0.05$; Fig. $5 A$ ). In contrast, in $R I M 1 \alpha^{-/-}$mice, no further increase in PPF after SE was 

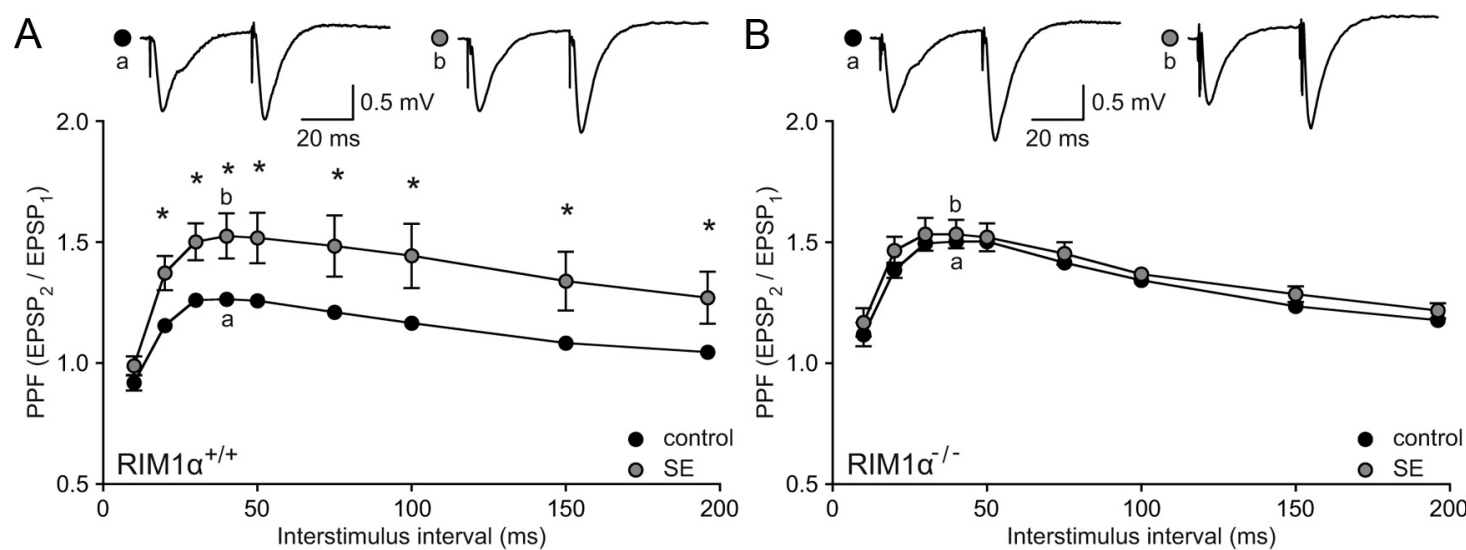

C RIM1 ${ }^{+/+}$control

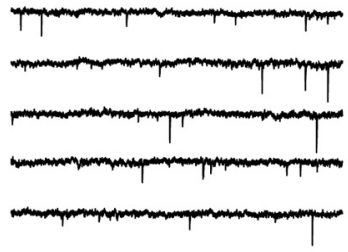

D

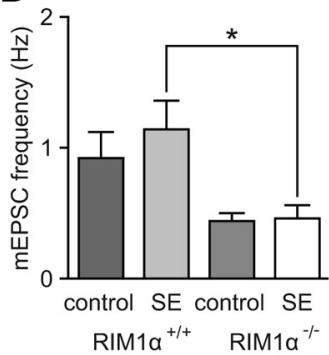

H $\quad$ RIM1a $^{+/+}$control

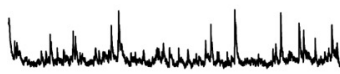
"

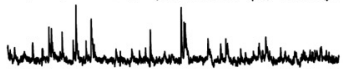

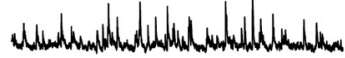

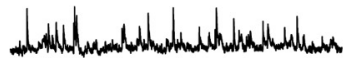

I

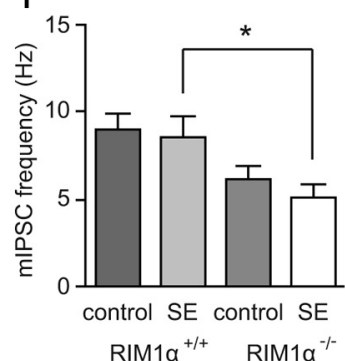

RIM1a $^{+/+}$SE

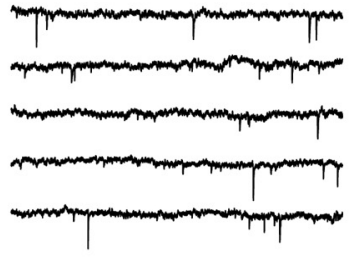

$\mathrm{E}$

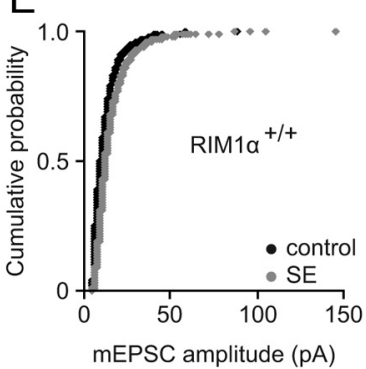

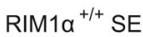

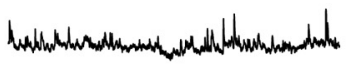

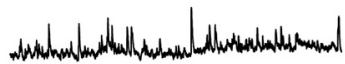

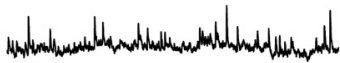

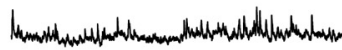

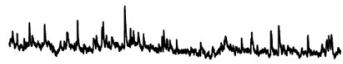

$\mathrm{J}$

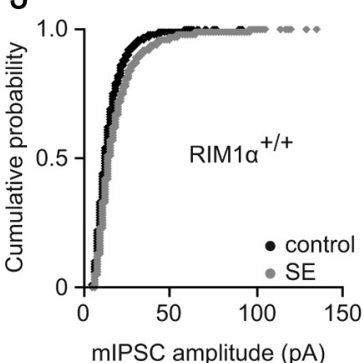

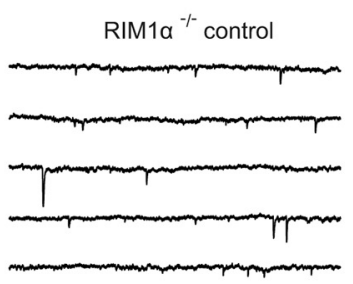

$\mathrm{F}$

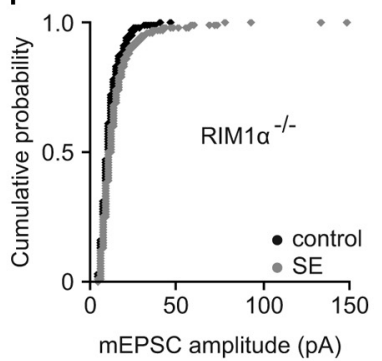

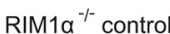

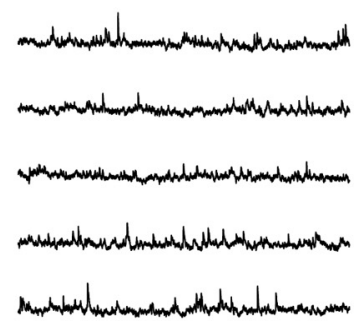

$\mathrm{K}$

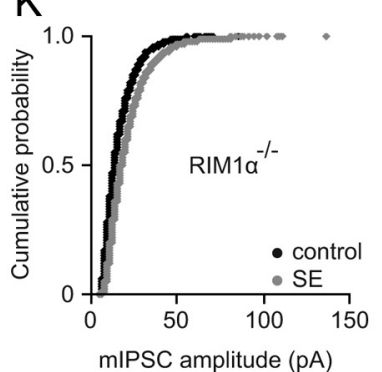

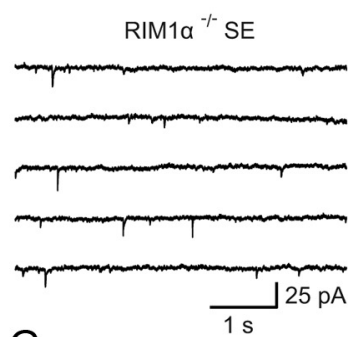

G

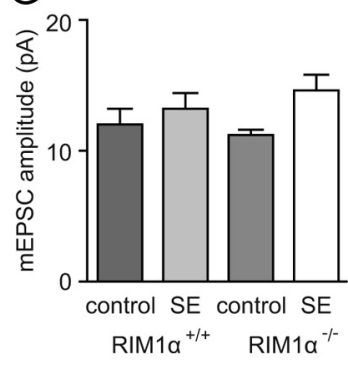

$\mathrm{RIM}^{-r}{ }^{-r} \mathrm{SE}$
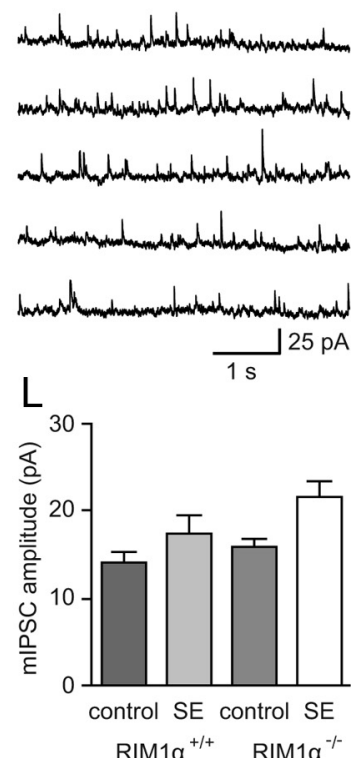

Figure 5. SE-induced functional changes in $R I M 1 \alpha^{-/-}$versus $R I M 1 \alpha^{+/+}$mice. $A, B$, Analysis of PPF at Schaffer collateral CA1 pyramidal neuron synapses. Representative recordings of field EPSPs with an interpulse interval of $40 \mathrm{~ms}$ are shown above the graphs. PPF was quantified as the ratio of field EPSP amplitudes (EPSP/EPSP $)$ and plotted against the interstimulus interval. $A$ significant increase in PPF was observed after SE in $R I M 1 \alpha^{+/+}\left({ }^{*} p<0.05\right.$, one-way ANOVA with Dunnett's posttest; $\left.\boldsymbol{A}\right)$ but not in $R I M 1 \alpha^{-/-}$animals $(\boldsymbol{B}) . n=5$ for all groups. $\boldsymbol{C}-\mathbf{G}$, Properties of $m$ EPSCS. C, Representative traces of mEPSCs in CA1 pyramidal neurons from $R I M 1 \alpha^{+/+}$and $R I M 1 \alpha^{-/-}$mice with and without previous SE (as indicated on top). RIM1 $\alpha^{+/+}$control and SE, $n=$ 8; RIM1 $\alpha^{-/-}$control, $n=9$; and SE, $n=10$. D. Analysis of mEPSC frequency. A significant effect of genotype, but not of previous SE, was observed ( $p=0.0004$ and $p=0.42$, respectively; two-way ANOVA). *Significance in Bonferroni posttest, $p<0.05$. $\boldsymbol{E}-\boldsymbol{G}$, Analysis of mEPSC amplitude. Both cumulative amplitude distribution histograms $(\boldsymbol{E}, \boldsymbol{F})$ and $($ Figure legend continues.) 
observed (Fig. $5 B$ ). This may indicate that $R I M 1 \alpha^{+/+}$mice react to an episode of SE with a homeostatic reduction in synaptic release, while $R I M 1 \alpha^{-/-}$mice are not capable of further decreasing release probability, thus lacking such post-SE homeostasis.

We next examined the properties of mEPSCs (see Materials and Methods, above). Representative mEPSC traces are shown in Figure $5 C$. The frequency of mEPSCs is determined by the number and release probability of excitatory synapses. SE caused no change of mEPSC frequency in RIM1 $\alpha^{+/+}$mice (Fig. 5D), possibly because of an aggregate effect of synaptic sprouting and synaptogenesis (Fig. 4) and decreased release probability. Likewise, no changes in mEPSC frequency were observed in $R I M 1 \alpha^{-/-}$ mice after SE (Fig. 5D), in which release probability was unchanged and synaptic sprouting was severely reduced. A two-way ANOVA with Bonferroni posttest confirmed a lack of effect of previous SE, but revealed a significant effect of genotype on mEPSC frequency $(p=0.0004 ; p<0.05$ in Bonferroni posttest; Fig. $5 D$ ). An analysis of mean mEPSC amplitude revealed small but significant effects of previous SE $(p<0.036)$, but not of genotype, without significant individual group differences (Fig. $5 E-G)$. A similar picture was observed when mIPSCs were examined (for representative mIPSC traces shown, see Fig. 5H). Significant effects of genotype were observed on mIPSC frequency $(p=0.0021 ; p<0.05$ in Bonferroni posttest; Fig. $5 I)$ and significant effects of previous SE on mIPSC amplitude $(p=0.0087$, two-way ANOVA; Fig. 5J-L).

\section{SE-induced alterations in the expression level of RIM1 $\alpha$ at the chronic epileptic stage}

The observed increase in paired-pulse facilitation in the chronic phase after SE could be the consequence of a decrease in RIM1 $\alpha$ levels. To address this hypothesis, we subjected mice to pilocarpine-induced SE and microdissected the hippocampal DG, CA3, and CA1 subregions at three timepoints after SE: the acute phase ( $6 \mathrm{~h}$ after SE), the beginning of the latency stage ( $24 \mathrm{~h}$ after SE), and the chronic phase (28 d after SE). We quantified mRNA levels of RIM $1 \alpha, \operatorname{RIM} 2 \alpha$, and RIM $1 \beta$ by quantitative real-time RT-PCR with synaptophysin as a reference gene to account for neuronal cell loss $(n=5$ in all groups, $n=4$ chronic controls). Whereas we did not detect any changes in RIM1 $\alpha$ mRNA expression levels early after SE (6 and 24 h; Fig. 6A), we observed a significant reduction of mRNA expression in the DG (25\%, Mann-Whitney $U$ test, $p<0.05)$ and CA1 (30\%, MannWhitney $U$ test, $p<0.05$ ) regions but not in CA3 $28 \mathrm{~d}$ after SE. RIM2 $\alpha$ was expressed throughout the hippocampus at much lower levels than RIM1 $\alpha$. After SE, the expression levels of RIM $2 \alpha$ were not altered except for $24 \mathrm{~h}$ after SE in the CA3 region, where a 1.4-fold increase was measured (Mann-Whitney $U$ test, $p<0.01$; Fig. $6 B$ ). RIM1 $\beta$ mRNA levels were very low in

\footnotetext{
(Figure legend continued.) mean mEPSC amplitude \pm SEM ( $G$ ) are shown. For mean mEPSC amplitudes, a significant effect of previous $\mathrm{SE}$, but not genotype, was observed ( $p=0.036$ and $p=0.75$, respectively; two-way ANOVA). Bonferroni posttests were not significant. $\boldsymbol{H}-\boldsymbol{L}$, Properties of mIPSCS. $\boldsymbol{H}$, Representative traces of mIPSCs in CA1 pyramidal neurons from $R I M 1 \alpha^{+/+}$ and $R I M 1 \alpha^{-/-}$mice with and without previous SE (as indicated on top). Numbers for the different groups are as for mEPSC recordings. I, Analysis of mEPSC frequency. A significant effect of genotype, but not of previous SE, was observed ( $p=0.0021$ and $p=0.4$, respectively; two-way ANOVA). *Significance in Bonferroni posttest, $p<0.05$. J-L, Analysis of mIPSC amplitude. Both cumulative amplitude distribution histograms $(\boldsymbol{J}, \boldsymbol{K})$ and mean mIPSC amplitude \pm SEM $(\boldsymbol{L})$ are shown. For mean mIPSC amplitudes, a significant effect of previous $S E$, but not genotype, was observed ( $p=0.0087$ and $p=0.087$, respectively; two-way ANOVA). Bonferroni posttests were not significant.
}
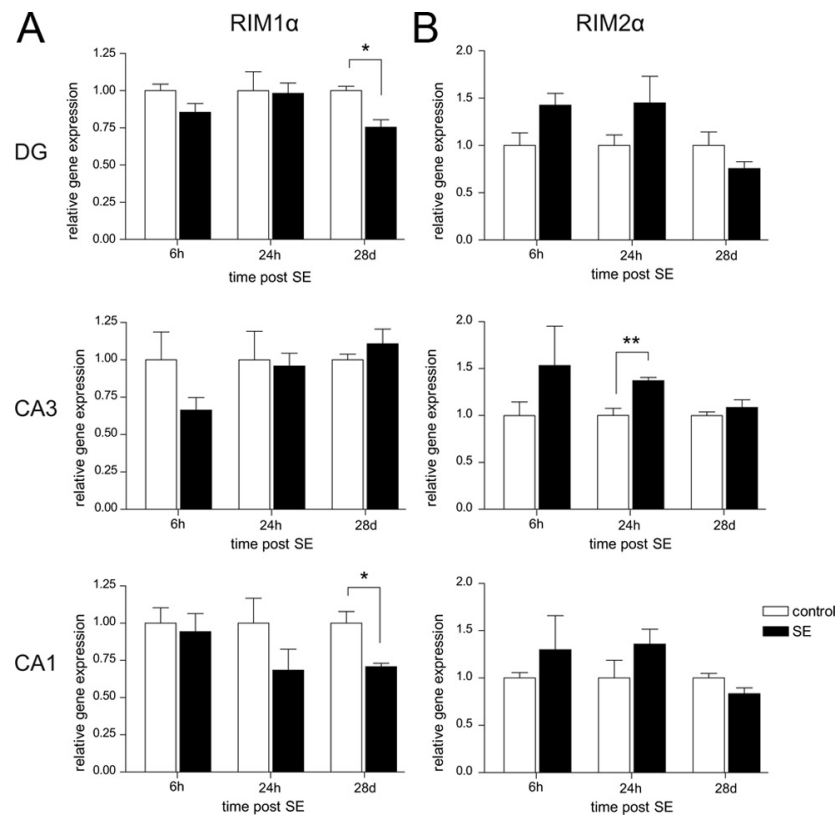

Figure 6. SE-induced changes in the expression level of RIM1 $\alpha$ in the chronic phase. $A, B$ Expression levels of the $\alpha$-RIM subunits after pilocarpine-induced SE was examined by quantitative real-time RT-PCR using the synaptic vesicle protein synaptophysin as reference gene ( $n=5$ for all groups; chronic control, $n=4$ ). Hippocampal subregions CA1, CA3, and DG were microdissected $6 \mathrm{~h}, 24 \mathrm{~h}$, and $28 \mathrm{~d}$ after SE. $\boldsymbol{A}$, A significant decrease in RIM $1 \alpha$ mRNA levels was observed on day 28 after SE in DG and CA1 region ( ${ }^{*} p<0.05$, Mann-Whitney $U$ test). $\boldsymbol{B}, A n$ upregulation of RIM2 $\alpha$ was determined $24 \mathrm{~h}$ after SE in the CA3 region $\left({ }^{* *} p<0.05\right.$, MannWhitney $U$ test). Error bars indicate mean \pm SEM.

control and in SE-experienced mice and did not exhibit any SEinduced changes (data not shown). These results reveal a subregion-specific reduced expression of RIM1 $\alpha$ in the chronic period after pilocarpine-induced SE.

\section{Discussion}

Homeostatic synaptic plasticity is an intriguing phenomenon that has been mainly observed in in vitro systems. Conceptually, it is thought to be a prerequisite for maintaining the activity of a neuronal network within a physiological range. In many systems, homeostatic adaptations to long-term modifications of neuronal activity can be achieved by modulation of both presynaptic and postsynaptic functions (Vitureira et al., 2012). For example, presynaptic terminals in networks of cultured primary neurons responds to strong depolarization or ongoing neuronal activity with a form of adaptive plasticity called persistent presynaptic silencing/muting (Jiang et al., 2010). However, unequivocal evidence for in vivo homeostatic plasticity is still lacking.

At the molecular level, the presynaptic active zone protein RIM $1 \alpha$ has emerged as one downstream target of presynaptic silencing and as a central player in multiple forms of presynaptically mediated forms of plasticity (for review, see Mittelstaedt et al., 2010). Here, we have examined the in vivo effects of intense neuronal activity induced by application of pilocarpine on a $\operatorname{Rim} 1 \alpha$-deficient neuronal network with compromised synaptic vesicle priming and deficits in presynaptically mediated forms of plasticity. The results of our study reveal that even though the ablation of RIM $1 \alpha$ does not cause changes in basal EEG, RIM $1 \alpha$ deficiency results in a dramatically increased frequency of spontaneous recurrent seizures in the chronic phase after SE. This development of a hyperexcitable network is accompanied by neuropathological alterations that resemble human endfolium 
sclerosis and, surprisingly, a decrease in mossy fiber sprouting and astrogliosis. In wild-type mice, SE induces a significant subregion-specific downregulation of RIM $1 \alpha$ mRNA in the dentate gyrus and the CA1 region.

The markedly increased frequency of seizures in RIM1 $\alpha$ deficient mice is consistent with the loss of a homeostatic dampening mechanism that is normally recruited during epileptogenesis. Such an effect has been observed for other genetically altered mouse lines that exhibit more seizures in the chronic phase, e.g., mice overexpressing mGluR1, but compared with the dramatic effects observed in the present study, the increase is rather modest (Pitsch et al., 2007). In our case, the functional results have revealed that pairedpulse facilitation is increased after SE in wild-type mice, consistent with a homeostatic reduction in release probability and similar to the increase in PPF observed in RIM1 $\alpha^{--}$mice (Schoch et al., 2002). Interestingly, $\mathrm{SE}$ cannot induce a further increase in PPF in $R I M 1 \alpha^{-1-}$ mice. SE-induced changes have also been observed at other hippocampal synapses. At the mossy fiber-CA3 synapse, kainate-induced SE results in marked loss of paired-pulse facilitation and long-term potentiation (LTP) and a significant increase in the size of the readily releasable pool at excitatory synapses in the chronic phase (Goussakov et al., 2000). Intriguingly, the status-induced changes on mossy fiber LTP occur downstream of protein kinase A (PKA) (Goussakov et al., 2000) and RIM1 $\alpha$ has been shown to be both a direct substrate of PKA and required for PKA-mediated forms of presynaptic long-term potentiation (Castillo et al., 2002; Lonart et al., 2003; Fourcaudot et al., 2008). Thus, RIM1 $\alpha$ may be a key to different adaptive changes within the hippocampal network.

We detected a significant reduction in the mRNA levels of RIM1 $\alpha$ specifically in the dentate gyrus and the CA1 region during the chronic phase after SE in wild-type mice. This finding could support the idea that pathologically increased activity may cause homeostatic reductions in glutamate release via reduction of RIM1 $\alpha$ levels (Crawford and Mennerick, 2012), as for example shown in primary neuronal cultures after depolarization with high concentrations of potassium chloride (Jiang et al., 2010). In accordance with the SE-induced change in PPF observed in wildtype mice, this finding suggests that in response to SE, specific regions in the wild-type brain react with adaptive responses that cannot be engaged in the RIM $1 \alpha$ knock-out brain. Interestingly, both regions with reduced RIM1 $\alpha$ mRNA levels, the DG and the CA1 region, exhibit aberrant neuronal connectivity in the chronic phase after pilocarpine treatment, in particular retrograde sprouting of the mossy fibers, CA1 neurons into area CA3, subicular neurons into area $\mathrm{CA} 1$, and increased connectivity between CA1 neurons and between the subicular and hilar cells (Lehmann et al., 2001).

Surprisingly, chronic EEG recordings revealed that the acute pilocarpine-induced SE was largely not different when comparing $R I M 1 \alpha^{-1-}$ and wild-type mice, even though there are manifold changes in the properties of different synapses. These results suggest that a network with a globally reduced synaptic vesicle priming rate does not show in itself an altered excitability, most likely due to counteracting effects in different elements of the neuronal network. Thus, our studies of RIM1 $\alpha$ yield a complex picture, in which the loss of RIM1 $\alpha$ is compensated within the network but leaves it incapable of mediating adaptive changes to strong neuronal activity. As a consequence, in $R I M 1 \alpha^{-/-}$mice, a markedly increased propensity to generate seizures is observed.

How could changes in RIM $1 \alpha$ levels contribute to presynaptic homeostasis? RIM1 $\alpha$ has been shown to directly regulate synaptic vesicle priming by activating Munc13-1 and to control presynaptic $\mathrm{Ca}^{2+}$-channel density and $\mathrm{Ca}^{2+}$-channel synaptic vesicle cou- pling (Deng et al., 2011; Han et al., 2011; Kaeser et al., 2011). In cell culture, a period of increased activity has been shown to result in presynaptic silencing caused by the targeted degradation of the synaptic vesicle priming proteins RIM1 $\alpha$ and Munc13-1 (Jiang et al., 2010). One open question in this regard was whether in vivo depolarizing insults can induce presynaptic silencing rapidly and strongly enough to provide endogenous neuroprotection. The observation that $\mathrm{SE}$ is unchanged could be explained if wild-type synapses are presynaptically silenced in response to pilocarpine to the same degree as the constitutively silenced RIM1 $\alpha$-deficient synapses. However, the inability to further decrease glutamate release in response to increased activity in the $\operatorname{RIM} 1 \alpha$-deficient neuronal network might result in the shortened latency to the onset of the first seizure.

Unexpectedly, the very large increase in seizure frequency observed in $R I M 1 \alpha^{-1-}$ mice does not result in more severe neuropathological alterations but rather manifests itself in a pattern resembling endfolium sclerosis in human TLE patients, which has not been previously described in genetic mouse models of epilepsy. Endfolium sclerosis is characterized by restricted hilar neuronal cell loss and granule cell dispersion in the DG but lack of substantial neuronal degeneration in other hippocampal subfields (Margerison and Corsellis, 1966; Thom et al., 2005). Atypical patterns of mesial temporal sclerosis have been discussed as the correlate of potentially variable rates of hippocampal neuronal maturation, which reflect individual vulnerability and cellprotective mechanisms in different hippocampal subfields (Van Paesschen et al., 1997; Blümcke et al., 2007). Indeed, our present data suggest a region-specific role of presynaptic molecules, i.e., $R I M 1 \alpha^{-1-}$, in setting the vulnerability of specific hippocampal neurons for degeneration. Even though previous analyses of the structural organization of RIM1 $\alpha$-deficient brains did not reveal any overt alterations (Castillo et al., 2002; Schoch et al., 2002), we cannot exclude that the different patterns and the severity of structural changes observed in the chronic phase after SE in the $R I M 1 \alpha^{-/-}$hippocampus compared with wild-type controls may reflect an aberrant network connectivity in the RIM1 $\alpha$ mutants that developed during ontogenesis. It could be hypothesized that in the constitutive RIM1 $\alpha$ knock-out glutamate release is decreased in most neurons, as in situ hybridization experiments revealed a ubiquitous expression of RIM1 $\alpha$ throughout the brain (Schoch et al., 2006). However, we did not detect a concomitant reduction in global excitability, suggesting that the system adapts to the constitutive lack of RIM $1 \alpha$. At the same time, a complete lack of RIM $1 \alpha$ in constitutive knock-outs would entail a loss of the RIM1 $\alpha$-dependent homeostatic mechanism that would normally act to curtail hyperexcitability. This loss of adaptive potential in turn might explain why the strong pathophysiological stimulation induced by pilocarpine results in such a dramatic increase in seizure frequency. However, it was recently shown that region-specific deletion of RIM1 reproduces a subset of the behavioral abnormalities observed in the constitutive RIM1 $\alpha^{-/-}$ mice (Haws et al., 2012), indicating that these phenotypes are not the consequence of a widespread aberrant network but of the absence of RIM $1 \alpha$ in a subset of neurons.

Recently, presynaptic proteins have emerged as potential antiepileptic drug targets, e.g., the synaptic vesicle protein SV2A as the high-affinity binding site for levetiracetam (Lynch et al., 2004). Like RIM1 $\alpha$, SV2A has been implied to be involved in the molecular mechanisms underlying both priming — by rendering primed synaptic vesicles competent for $\mathrm{Ca}^{2+}$-induced exocytosis (Chang and Südhof, 2009) and by enhancing release probability at quiescent synapses (Custer et al., 2006) — and presynaptic ho- 
meostatic plasticity as a target of miR-485 (Cohen et al., 2011). Blocking of miR-485 in turn reverses the homeostatic reduction in synaptic connectivity after incubation of neuronal cultures for $5 \mathrm{~d}$ with BiC/4-AP. Furthermore, mice deficient for SV2A exhibit spontaneous epileptic seizures (Crowder et al., 1999; Janz et al., 1999), as do knock-out mice for the synaptic vesicle protein synapsin (Li et al., 1995; Rosahl et al., 1995) and the active zone protein Bassoon (Altrock et al., 2003). In this respect, it will be critical to determine in detail how the presynaptic release machinery contributes to or is affected by the development of epileptogenesis.

Due to the multiple alterations in synaptic properties in the $R I M 1 \alpha^{-/-}$mice, it is currently difficult to attribute the proepileptic phenotype to a specific form of synaptic plasticity at a defined synapse. Rather, the observed phenotype could be the consequence of the concomitant failure of multiple forms of synaptic plasticity to be correctly induced. Further analyses using mice, in which RIM1 $\alpha$ is selectively ablated in defined subsets of neurons, e.g., excitatory versus inhibitory, will be required to resolve these open questions.

\section{References}

Altrock WD, tom Dieck S, Sokolov M, Meyer AC, Sigler A, Brakebusch C, Fässler R, Richter K, Boeckers TM, Potschka H, Brandt C, Löscher W, Grimberg D, Dresbach T, Hempelmann A, Hassan H, Balschun D, Frey JU, Brandstätter JH, Garner CC, et al. (2003) Functional inactivation of a fraction of excitatory synapses in mice deficient for the active zone protein bassoon. Neuron 37:787-800.

Bausch SB, He S, Petrova Y, Wang XM, McNamara JO (2006) Plasticity of both excitatory and inhibitory synapses is associated with seizures induced by removal of chronic blockade of activity in cultured hippocampus. J Neurophysiol 96:2151-2167.

Becker AJ, Pitsch J, Sochivko D, Opitz T, Staniek M, Chen CC, Campbell KP, Schoch S, Yaari Y, Beck H (2008) Transcriptional upregulation of Cav3.2 mediates epileptogenesis in the pilocarpine model of epilepsy. J Neurosci 28:13341-13353.

Blümcke I, Beck H, Lie AA, Wiestler OD (1999) Molecular neuropathology of human mesial temporal lobe epilepsy. Epilepsy Res 36:205-223.

Blümcke I, Schewe JC, Normann S, Brüstle O, Schramm J, Elger CE, Wiestler OD (2001) Increase of nestin-immunoreactive neural precursor cells in the dentate gyrus of pediatric patients with early-onset temporal lobe epilepsy. Hippocampus 11:311-321.

Blümcke I, Pauli E, Clusmann H, Schramm J, Becker A, Elger C, Merschhemke M, Meencke HJ, Lehmann T, von Deimling A, Scheiwe C, Zentner J, Volk B, Romstöck J, Stefan H, Hildebrandt M (2007) A new clinico-pathological classification system for mesial temporal sclerosis. Acta Neuropathol 113:235-244.

Branco T, Staras K, Darcy KJ, Goda Y (2008) Local dendritic activity sets release probability at hippocampal synapses. Neuron 59:475-485.

Calakos N, Schoch S, Südhof TC, Malenka RC (2004) Multiple roles for the active zone protein RIM1alpha in late stages of neurotransmitter release. Neuron 42:889-896.

Castillo PE, Schoch S, Schmitz F, Südhof TC, Malenka RC (2002) RIMlalpha is required for presynaptic long-term potentiation. Nature 415:327-330.

Cavazos JE, Zhang P, Qazi R, Sutula TP (2003) Ultrastructural features of sprouted mossy fiber synapses in kindled and kainic acid-treated rats. J Comp Neurol 458:272-292.

Chang WP, Südhof TC (2009) SV2 renders primed synaptic vesicles competent for Ca2+-induced exocytosis. J Neurosci 29:883-897.

Chevaleyre V, Heifets BD, Kaeser PS, Südhof TC, Purpura DP, Castillo PE (2007) Endocannabinoid-mediated long-term plasticity requires cAMP/ PKA signaling and RIMlalpha. Neuron 54:801-812.

Cohen JE, Lee PR, Chen S, Li W, Fields RD (2011) MicroRNA regulation of homeostatic synaptic plasticity. Proc Natl Acad Sci USA 108:11650-11655.

Crawford DC, Mennerick S (2012) Presynaptically silent synapses: dormancy and awakening of presynaptic vesicle release. Neuroscientist $18: 216-223$
Crowder KM, Gunther JM, Jones TA, Hale BD, Zhang HZ, Peterson MR, Scheller RH, Chavkin C, Bajjalieh SM (1999) Abnormal neurotransmission in mice lacking synaptic vesicle protein 2A (SV2A). Proc Natl Acad Sci U S A 96:15268-15273.

Custer KL, Austin NS, Sullivan JM, Bajjalieh SM (2006) Synaptic vesicle protein 2 enhances release probability at quiescent synapses. J Neurosci 26:1303-1313.

Deng L, Kaeser PS, Xu W, Südhof TC (2011) RIM proteins activate vesicle priming by reversing autoinhibitory homodimerization of Munc13. Neuron 69:317-331.

Fink L, Seeger W, Ermert L, Hänze J, Stahl U, Grimminger F, Kummer W, Bohle RM (1998) Real-time quantitative RT-PCR after laser-assisted cell picking. Nat Med 4:1329-1333.

Fourcaudot E, Gambino F, Humeau Y, Casassus G, Shaban H, Poulain B, Lüthi A (2008) cAMP/PKA signaling and RIM1alpha mediate presynaptic LTP in the lateral amygdala. Proc Natl Acad Sci U S A 105:15130-15135.

Galvan CD, Hrachovy RA, Smith KL, Swann JW (2000) Blockade of neuronal activity during hippocampal development produces a chronic focal epilepsy in the rat. J Neurosci 20:2904-2916.

Goussakov IV, Fink K, Elger CE, Beck H (2000) Metaplasticity of mossy fiber synaptic transmission involves altered release probability. J Neurosci 20:3434-3441.

Han EB, Stevens CF (2009) Development regulates a switch between postand presynaptic strengthening in response to activity deprivation. Proc Natl Acad Sci U S A 106:10817-10822.

Han Y, Kaeser PS, Südhof TC, Schneggenburger R (2011) RIM determines $\mathrm{Ca}(2)+$ channel density and vesicle docking at the presynaptic active zone. Neuron 69:304-316.

Haws ME, Kaeser PS, Jarvis DL, Südhof TC, Powell CM (2012) Regionspecific deletions of RIM1 reproduce a subset of global RIMlalpha $(-/-)$ phenotypes. Genes Brain Behav 11:201-213.

Houser CR (1992) Morphological changes in the dentate gyrus in human temporal lobe epilepsy. Epilepsy Res Suppl 7:223-234.

Howard AL, Neu A, Morgan RJ, Echegoyen JC, Soltesz I (2007) Opposing modifications in intrinsic currents and synaptic inputs in post-traumatic mossy cells: evidence for single-cell homeostasis in a hyperexcitable network. J Neurophysiol 97:2394-2409.

Janz R, Goda Y, Geppert M, Missler M, Südhof TC (1999) SV2A and SV2B function as redundant $\mathrm{Ca}^{2+}$ regulators in neurotransmitter release. Neuron 24:1003-1016.

Jiang X, Litkowski PE, Taylor AA, Lin Y, Snider BJ, Moulder KL (2010) A role for the ubiquitin-proteasome system in activity-dependent presynaptic silencing. J Neurosci 30:1798-1809.

Kaeser PS, Südhof TC (2005) RIM function in short- and long-term synaptic plasticity. Biochem Soc Trans 33:1345-1349.

Kaeser PS, Kwon HB, Chiu CQ, Deng L, Castillo PE, Südhof TC (2008a) RIM1alpha and RIM1beta are synthesized from distinct promoters of the RIM1 gene to mediate differential but overlapping synaptic functions. J Neurosci 28:13435-13447.

Kaeser PS, Kwon HB, Blundell J, Chevaleyre V, Morishita W, Malenka RC, Powell CM, Castillo PE, Südhof TC (2008b) RIMlalpha phosphorylation at serine- 413 by protein kinase $\mathrm{A}$ is not required for presynaptic long-term plasticity or learning. Proc Natl Acad Sci U S A 105:14680-14685.

Kaeser PS, Deng L, Wang Y, Dulubova I, Liu X, Rizo J, Südhof TC (2011) RIM proteins tether $\mathrm{Ca}^{2+}$ channels to presynaptic active zones via a direct PDZ-domain interaction. Cell 144:282-295.

Lazarevic V, Schöne C, Heine M, Gundelfinger ED, Fejtova A (2011) Extensive remodeling of the presynaptic cytomatrix upon homeostatic adaptation to network activity silencing. J Neurosci 31:10189-10200.

Lehmann TN, Gabriel S, Eilers A, Njunting M, Kovacs R, Schulze K, Lanksch WR, Heinemann U (2001) Fluorescent tracer in pilocarpine-treated rats shows widespread aberrant hippocampal neuronal connectivity. Eur J Neurosci 14:83-95.

Li L, Chin LS, Greengard P, Copeland NG, Gilbert DJ, Jenkins NA (1995) Localization of the synapsin II (SYN2) gene to human chromosome 3 and mouse chromosome 6. Genomics 28:365-366.

Lonart G, Schoch S, Kaeser PS, Larkin CJ, Südhof TC, Linden DJ (2003) Phosphorylation of RIMlalpha by PKA triggers presynaptic long-term potentiation at cerebellar parallel fiber synapses. Cell 115:49-60.

Lynch BA, Lambeng N, Nocka K, Kensel-Hammes P, Bajjalieh SM, Matagne A, Fuks B (2004) The synaptic vesicle protein SV2A is the binding site 
for the antiepileptic drug levetiracetam. Proc Natl Acad Sci U S A 101:9861-9866.

Margerison JH, Corsellis JA (1966) Epilepsy and the temporal lobes: a clinical, electroencephalographic and neuropathological study of the brain in epilepsy, with particular reference to the temporal lobes. Brain 89:499-530.

Mittelstaedt T, Alvaréz-Baron E, Schoch S (2010) RIM proteins and their role in synapse function. Biol Chem 391:599-606.

Moulder KL, Meeks JP, Shute AA, Hamilton CK, de Erausquin G, Mennerick S (2004) Plastic elimination of functional glutamate release sites by depolarization. Neuron 42:423-435.

Moulder KL, Jiang X, Taylor AA, Olney JW, Mennerick S (2006) Physiological activity depresses synaptic function through an effect on vesicle priming. J Neurosci 26:6618-6626.

Murthy VN, Schikorski T, Stevens CF, Zhu Y (2001) Inactivity produces increases in neurotransmitter release and synapse size. Neuron 32:673-682.

Pelkey KA, Topolnik L, Yuan XQ, Lacaille JC, McBain CJ (2008) Statedependent cAMP sensitivity of presynaptic function underlies metaplasticity in a hippocampal feedforward inhibitory circuit. Neuron 60:980-987.

Pitsch J, Schoch S, Gueler N, Flor PJ, van der Putten H, Becker AJ (2007) Functional role of mGluR1 and mGluR4 in pilocarpine-induced temporal lobe epilepsy. Neurobiol Dis 26:623-633.

Pozo K, Goda Y (2010) Unraveling mechanisms of homeostatic synaptic plasticity. Neuron 66:337-351.
Rosahl TW, Spillane D, Missler M, Herz J, Selig DK, Wolff JR, Hammer RE, Malenka RC, Südhof TC (1995) Essential functions of synapsins I and II in synaptic vesicle regulation. Nature 375:488-493.

Schoch S, Castillo PE, Jo T, Mukherjee K, Geppert M, Wang Y, Schmitz F, Malenka RC, Südhof TC (2002) RIMlalpha forms a protein scaffold for regulating neurotransmitter release at the active zone. Nature 415:321-326.

Schoch S, Mittelstaedt T, Kaeser PS, Padgett D, Feldmann N, Chevaleyre V, Castillo PE, Hammer RE, Han W, Schmitz F, Lin W, Südhof TC (2006) Redundant functions of RIM1alpha and RIM2alpha in $\mathrm{Ca}(2+)$-triggered neurotransmitter release. EMBO J 25:5852-5863.

Thom M, Zhou J, Martinian L, Sisodiya S (2005) Quantitative post-mortem study of the hippocampus in chronic epilepsy: seizures do not inevitably cause neuronal loss. Brain 128:1344-1357.

Van Paesschen W, Revesz T, Duncan JS, King MD, Connelly A (1997) Quantitative neuropathology and quantitative magnetic resonance imaging of the hippocampus in temporal lobe epilepsy. Ann Neurol 42:756-766.

Vitureira N, Letellier M, Goda Y (2012) Homeostatic synaptic plasticity: from single synapses to neural circuits. Curr Opin Neurobiol 22:516-521.

Wieser HG (2004) ILAE commission report: mesial temporal lobe epilepsy with hippocampal sclerosis. Epilepsia 45:695-714.

Wyler AR, Dohan FC, Schweitzer JB, Berry AD (1992) A grading system for mesial temporal pathology (hippocampal sclerosis) from anterior temporal lobectomy. J Epilepsy 5:220-225. 